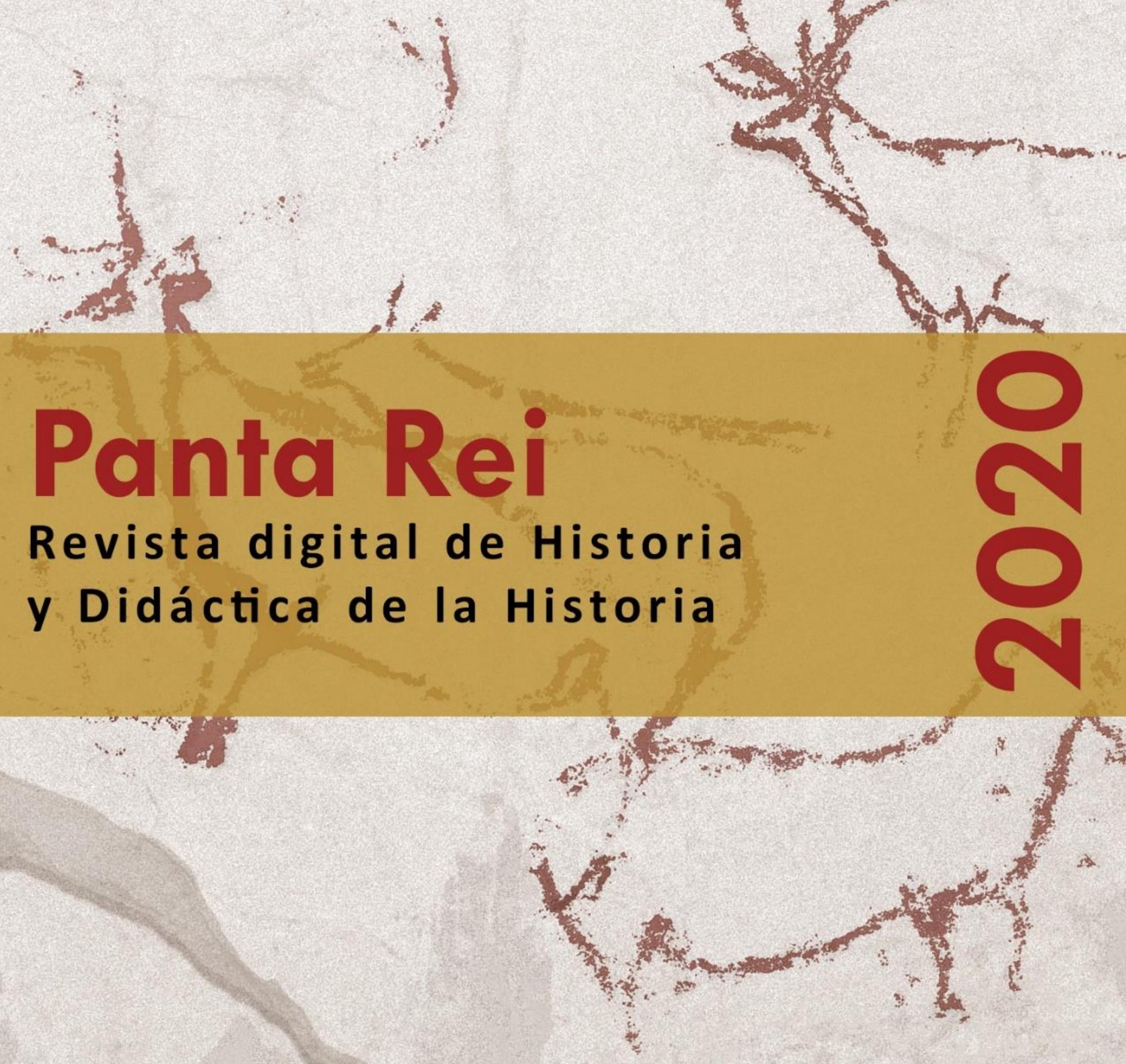




\section{0}

Revista anual

Fecha de inicio: 1995

RevistaPantaRei.pantarei@um.es

\section{Edita:}

Centro de Estudios del Próximo Oriente y la

Antigüedad Tardía - CEPOAT

Edificio Universitario Saavedra Fajardo.

Universidad de Murcia

C/ Actor Isidoro Máiquez, 9

30007 - MURCIA - ESPAÑA

Teléfono: $(+34) 868883890$

cepoat@um.es

Web: www.um.es/cepoat/pantarei

Ediciones de la Universidad de Murcia - EDITUM

Edificio Pleiades. Campus de Espinardo.

Universidad de Murcia

$\mathrm{C} /$ Campus, s/n

30100 - MURCIA - ESPAÑA

Teléfono: $(+34) 868883013$

En portada: calco de las pinturas rupestres de la editum@um.es

Web: https://www.um.es/web/editum/

Cueva del Niño. García Moreno et al., 2016.

Edición 2020

ISSNe: 2386-8864

Responsables de los textos: sus autores.

ISSN: $1136-2464$

Depósito legal: MU-966-1995

Responsable de la presente edición: Consejo Editorial de Panta Rei. 


\section{CONSEJO DE REDACCIÓN}

Coordinador editorial

Egea Vivancos, Alejandro [Didáctica de las Ciencias Sociales, Universidad de Murcia]

Secretaria

Arias Ferrer, Laura [Didáctica de las Ciencias

Sociales, Universidad de Murcia]

Editores

Jiménez Vialás, Helena [Historia Antigua, Universidad de Murcia]

Martínez Gil, Tània [Didáctica de las Ciencias

Sociales, Universidad de Barcelona]

Meseguer Gil, Antonio José [Historiador, Profesor de

Secundaria]

Ortiz García, Jónatan [Arqueología, Universidad de

Alcalá de Henares]

Romero Molero, Alberto [Arqueología, Universidad

Isabel I]

Sáez Giménez, David Omar [Historiador, Profesor

de Secundaria]

Sáez Rosenkranz, Isidora V. [Didáctica de las

Ciencias Sociales, Universidad de Barcelona]

Sánchez Mondejar, Celso Miguel [Arqueólogo,

Patrimonio Inteligente]

Responsable informático

Martínez García, José Javier [CEPOAT, Universidad de Murcia]

Responsables de traducción y corrección lingüística Martínez Martínez, Cristina [Profesora de Secundaria, Sociedad Española de Lenguas Modernas] Albaladejo Albaladejo, Sara [ISEN-Universidad de Murcia]

\section{CONSEJO ASESOR}

Adroher Auroux, Andrés María [Arqueología, Universidad de Granada]

Albero Muñoz, $M^{a}$ del Mar [H. ${ }^{a}$ del Arte, Universidad de Murcia]

Alia Miranda, Francisco [Historia Contemporánea, UCLM]

Arciniega García, Luis [Historia del Arte, Universidad de Valencia]

Barrio Barrio, Juan Antonio [Historia Medieval,

Universidad de Alicante]

Castellano i Solé, Núria [Egiptología, Schola

Didàctica Activa S.L.]

Chapman, Arthur [History Education, University

College of London, Reino Unido]

Cid López, Rosa María [Historia Antigua, Universidad de Oviedo]

Cobacho López, Ángel [Derecho, Universidad de Murcia]

Cuenca López, José María [Didáctica de las Ciencias Sociales, Universidad de Huelva]
Egea Bruno, Pedro M. ${ }^{a}$ [Historia Contemporánea, Universidad de Murcia]

Feijoo Martínez, Santiago [Arqueología, Consorcio

Ciudad Monumental de Mérida]

García Atienzar, Gabriel [Prehistoria, Universidad de

Alicante]

Ginestí Rosell, Anna [Filología Clásica, Katholische

Universität Eichstätt-Ingolstadt]

González Monfort, Neus [Didáctica de las

Ciencias Sociales, Universidad Autónoma de

Barcelona]

González Soutelo, Silvia [Arqueología, Universidad de Vigo]

Haber Uriarte, María [Prehistoria, Universidad de Murcia]

Hernández de la Fuente, David [Filología Clásica, Universidad Complutense]

Hutson, Scott R. [Anthropology, University of Kentucky, EEUU]

Igual Luis, David [Historia Medieval, UCLM]

Irigoyen López, Antonio [Historia Moderna,

Universidad de Murcia]

Jover Maestre, Francisco Javier [Prehistoria,

Universidad de Alicante]

Mahony, Simon [Digital Humanities, University College of London, Reino Unido]

Marsilla de Pascual, Francisco Reyes [Técnicas

historiográficas, Universidad de Murcia]

Martínez-Burgos García, Palma [H. ${ }^{a}$ del Arte, UCLM]

Mathis, Christian [Didaktik der Geschichte, PH Zürich]

Miralles Maldonado, José Carlos [Filología Clásica,

Universidad de Murcia]

Molina Gómez, José Antonio [Historia Antigua,

Universidad de Murcia]

Mónica Ghirardi [Historia Moderna, Universidad

Nacional de Córdoba, Argentina]

Navarro Espinach, Germán [Historia Medieval,

Universidad de Zaragoza]

Noguera Celdrán, José Miguel [Arqueología,

Universidad de Murcia]

Ortiz Heras, Manuel [Historia Contemporánea, UCLM]

Panzram, Sabine [Historia Antigua, Universität

Hamburg]

Pérez Molina, Miguel Emilio [Filología Clásica,

Universidad de Murcia]

Prados Martínez, Fernando [Arqueología,

Universidad de Alicante]

Sánchez lbáñez, Raquel [Didáctica de las Ciencias

Sociales, Universidad de Murcia]

Sancho Gómez, Miguel Pablo [Educación, UCAM]

Victoria Moreno, Diego [Historia Contemporánea,

UNED]

Vilar García, María José [Historia Contemporánea,

Universidad de Murcia]

Vivas Sainz, Inmaculada [H. ${ }^{a}$ del Arte, UNED]

Zamora López, José Ángel [Próximo Oriente Antiguo,

CCHS-CSIC] 



\section{Índice}

\section{Artículos}

Las ocupaciones paleolíticas en el sur de la provincia de Albacete

Noelia Sánchez Martínez

El elefante en las acuñaciones hispanocartaginesas

José Luis Aledo Martínez

La epigrafía votiva romana de Caldas de Montbui (Vallés Oriental, Barcelona) (ss. I-II d. C.). Un ejemplo de promoción de las élites provinciales de la tarraconensis en centros de aguas mineromedicinales

Jesús Sánchez Alguacil

Representación de la historia de España por medio de la filatelia. Estudio de los sellos diseñados por Gallego y Rey

Pedro Vázquez-Miraz

La representación del patrimonio arqueológico en los libros de texto de Educación Primaria: EI 109 contexto indígena canario como estudio de caso

A. José Farrujía, Carmen Ascanio Sánchez, Ulises Martín Herández y Cristo Manuel Hernández Gómez

La empatía como elemento para la adquisición del pensamiento histórico en alumnos de 129 bachillerato. Un estudio de caso centrado en la Guerra Civil española y el franquismo Sebastián Molina Puche y Adrián Salmerón Ayala

Fuentes orales para el desarrollo de la empatía histórica: un estudio en la formación del 155 profesorado de Educación Infantil

$M^{a}$. Teresa Carril-Merino, Beatriz Andreu-Mediero, Mercedes de la Calle Carrecedo y Esther López Torres

¿Qué aporta el género a la formación de docentes de historia? La valoración de la perspectiva de género entre los estudiantes del Máster de Profesor/Profesora en Educación Secundaria Helena Rausell Guillot

Educar para una ciudadanía crítica: una investigación a partir de los usos y finalidades de la historia escolar

Néstor Banderas Navarro

\section{Reseñas}

A. Brilli (2018). El viaje a Oriente, Madrid: A. Machado Libros, 390 págs Juan Álvarez García

Altamira (Hugh Hudson, 2016) 



\title{
Las ocupaciones paleolíticas en el sur de la provincia de Albacete
}

\author{
The Palaeolithic Occupations in the South of the Province of Albacete
}

\author{
Noelia Sánchez Martínez \\ Universidad de Murcia \\ noelia.sanchez8@um.es \\ (D) 0000-0001-7200-2185
}

Recibido: $28 / 01 / 2020$

Aceptado: 01/04/2020

\section{Resumen}

La Submeseta sur ha sido considerada como un paraje inhóspito para los grupos paleolíticos. En este estudio trataremos de demostrar que la parte de esta región localizada al sur de Albacete fue ocupada durante el Paleolítico inferior, medio y superior, y que, además de eso, ofrecería una gran cantidad de recursos hídricos, vegetales, faunísticos y líticos que harían de ella un lugar adecuado. Los hallazgos superficiales y las excavaciones llevadas a cabo en abrigos y cuevas reafirmarán la hipótesis que aquí planteamos y obtendremos de ellas información más concreta y precisa sobre los modos de vida de los habitantes paleolíticos de la Submeseta sur.

\section{Palabras clave}

Arqueología, Yacimientos, Historia Asentamientos, Prehistoria.

\begin{abstract}
The southern sub-plateau has always been considered an inhospitable place for the Paleolithic groups. In this study we will try to demonstrate that the part of this region located in the south of Albacete was occupied during the Lower, Middle and Upper Palaeolithic. Besides that, it would provide a great amount of water, vegetable, fauna and lithic resources that would make it a suitable place. The open-air findings and the excavations carried out in shelters and caves will reaffirm the hypothesis we are putting forward here, and we will obtain from them more concrete and precise information about the ways of life of the Palaeolithic inhabitants of the southern sub-plateau.
\end{abstract}

\section{local, Keywords}

Archaeology, Historic sites, Local History, Land Settlement, Prehistory.

Para citar este artículo: Sánchez Martínez, N. (2020). Las ocupaciones paleolíticas en el sur de la provincia de Albacete. Panta Rei: revista digital de Historia y didáctica de la Historia, 7-42. doi: $10.6018 /$ pantarei.444271 


\section{Introducción. Historia de la investigación y área geográfica}

El territorio de la actual provincia de Albacete siempre ha sido visto por los investigadores de la Prehistoria $y$, más concretamente, del Paleolítico, como una zona escasamente poblada o una zona de ocupación estacional, debido a las dificultades climáticas que suponía la vida en la Meseta durante el Paleolítico para los grupos cazadores-recolectores. Tradicionalmente se había pensado que los núcleos de habitación se restringieron a las zonas costeras de la península ibérica, en nuestro caso, la zona mediterránea. Los restos hallados en algunos yacimientos del interior podrían pertenecer a incursiones de las poblaciones del levante hacia el interior con una intencionalidad concreta (Corchón Rodríguez, 2002; Davidson, 1986; Straus, 1991). En cambio, en los últimos años, las nuevas investigaciones están sacando a la luz la existencia de una mayor cantidad de lugares con restos paleolíticos en el interior peninsular, lo cual ha generado variaciones en las interpretaciones propuestas (Alcaraz-Castaño, 2016; Cacho Quesada et al., 2010; Martín-Lerma, 2015). Este hecho nos lleva a pensar que, quizás, se han hallado menos vestigios debido a la carencia de proyectos de estudio que tuviesen a esta zona geográfica como protagonista y destacamos la necesidad de continuar y ampliar los que están en activo (García Moreno, 2014; Martín-Lerma, 2015).

En cuanto a la zona a la que se circunscribe nuestro estudio, las primeras investigaciones que se realizaron tuvieron lugar en los primeros años del siglo XX. Obermaier descubrió materiales tardenoisienses en el Abrigo de Alpera (Almansa) en 1916; en 1928 Brevil halló un yacimiento de materiales musterienses en el Canalizo del Rayo (Hellín); y no debemos olvidar el arte rupestre postpaleolítico, estudiado por autores como Cabré (García Moreno, 2014).

Ya en la segunda mitad del siglo XX comienza a aparecer más información con los hallazgos de yacimientos que siguen siendo clave en la comprensión del Paleolítico en el sur de Albacete, tales como la Cueva del Niño (Ayna), descubierta en 1970 (Almagro-Gorbea, 1971), el Abrigo del Molino del Vadico (Yeste) en los años 80, y una gran cantidad de yacimientos al aire libre hallados en las prospecciones realizadas por Jordán durante las décadas de los años 80 y 90 , para la realización de las cartas arqueológicas de diversos municipios de la provincia (Jordán Montés, 1992). También debemos destacar la recopilación y estudio de yacimientos del Paleolítico medio de la cuenca del río Mundo realizado por Serna en 1999, que incluye la mayoría de los yacimientos que se conocen actualmente de ese periodo en esa zona geográfica concreta.

El estudio que vamos a realizar se circunscribe a una zona geográfica delimitada y con una realidad muy compleja. Nos referimos a la zona de la Submeseta sur de la península ibérica, en su unión con las sierras de la Bética, que se encuentra en el sur de la provincia de Albacete. Esta zona se divide en tres áreas diferenciadas las cuales son: el Campo de Hellín, la cuenca del río Mundo y la cuenca del río Segura. Estas áreas tienen características geográficas diferentes, pero en nuestro estudio las trataremos como un conjunto, debido a su proximidad a la zona del litoral mediterráneo, y a las interrelaciones en cuanto a recursos que se dieron durante todo el Paleolítico.

La orografía que compone la zona geográfica objeto de nuestro estudio es muy diversa. Por un lado, el Campo de Hellín está compuesto por una serie de llanuras y elevaciones aisladas y de baja altura, y queda enclavado entre la sierra del Segura y la sierra de Alcaraz en su zona sur. 
A su vez, está surcado por ramblas de recogida de agua que van a desembocar al río Mundo en su cauce bajo, próximo a su unión con el río Segura. La existencia de estas ramblas y de diversos puntos de nacimiento de agua, hace de esta área un lugar óptimo para la presencia de grupos del Paleolítico que se establezcan ocasionalmente o estacionalmente junto a estos cursos hídricos. En el caso de las cuencas de los ríos Segura y Mundo, encontramos una morfología totalmente diferente. La acción de estos ríos y sus afluentes y situación en la sierra del Segura y la sierra de Alcaraz, en el límite de la Bética, provoca que nos enfrentemos a un entorno físico abrupto, con barrancos y gargantas. Además, ambas sierras se caracterizan por contar con sistemas kársticos gracias a los cuales existen cuevas y abrigos rocosos, e incluso grandes galerías (García Moreno, 2011).

Por último, debemos destacar, desde el inicio de este trabajo, que la mayoría de los yacimientos que aquí vamos a presentar son hallazgos realizados al aire libre, sobre los cuales solo se pudo realizar un estudio lítico en el mejor de los casos. Las excavaciones sistemáticas y científicas o los sondeos son algo excepcional. Aplicadas a los sitios mejor conservados o con mayor interés arqueológico, como puede ser El Palomar, nos han ofrecido una gran cantidad de datos que han permitido avanzar enormemente en el estudio del Paleolítico en el sur de Albacete (Peña Alonso, $2011)$.

Para la realización de este estudio hemos procedido al análisis de todas las publicaciones realizadas sobre el Paleolítico en esta zona geográfica, ya fuesen sobre un solo yacimiento, sobre un conjunto, o sobre áreas de captación o recursos disponibles. Además, hemos visitado la mayoría de yacimientos que disponen de una ubicación clara para comprobar su estado actual y fotografiarlos. En cuanto a la industria lítica y el resto de elementos hallados en los yacimientos que analizamos, hemos de indicar que no hemos podido tener acceso a ellos para realizar un estudio exhaustivo, el cual también habría sido demasiado amplio, al abarcar gran número de yacimientos y un área de estudio amplia. De este modo, basaremos nuestros análisis en las descripciones realizadas por los arqueólogos y prehistoriadores que descubrieron y estudiaron esos yacimientos previamente. Una vez reunida toda esta información, realizamos una síntesis de la misma, que presentamos a continuación, y establecemos unas conclusiones generales.

El objetivo que nos proponemos con esta publicación es realizar una visión actualizada de todos los yacimientos paleolíticos que han sido hallados en el sur de Albacete, analizar los aspectos tipo-tecnológicos de su industria lítica e intentar entender los modos de vida y habitación que tuvieron lugar en esta zona. Estas conclusiones, basadas en estudios previos y análisis realizados por otros investigadores, servirán como base teórica sobre la que sustentar posibles futuras intervenciones arqueológicas y para avanzar en el conocimiento del poblamiento paleolítico en esta zona de la Submeseta sur, un caso de estudio que puede ayudarnos a comprender la evolución de las investigaciones y la aplicación de sus cambios y hallazgos a la hora de comprender y explicar la Prehistoria.

\section{Los yacimientos paleolíticos en el sur de Albacete (Submeseta sur)}

En este estudio hemos tratado de localizar geográficamente todos los yacimientos con cronologías paleolíticas que están situados en el área objeto de estudio, reunir toda la información que los investigadores que trabajaron sobre ellos han producido y generar un estado actual de la cuestión del Paleolítico en el sur de Albacete. 
Muchos de los sitios arqueológicos que veremos a continuación son estaciones superficiales en las que los prospectores hallaron unas decenas de piezas líticas, en el mejor de los casos. Estos hallazgos, generalmente en posición secundaria, no pueden ser desechados a la ligera, sino que deben ser analizados con cautela para extraer toda la información posible sin realizar sobreinterpretaciones. En nuestro caso, trataremos de agrupar aquellos hallazgos de poca entidad que aparezcan en parajes próximos entre sí y analizaremos los datos tecnológicos aportados en las diversas publicaciones de cada sitio (Tabla 1).

Debemos puntualizar que varios de los yacimientos aquí mencionados y analizados contienen cronologías del Paleolítico medio y del superior. En estos casos hemos decidido incluirlas en la clasificación dentro del apartado del periodo del que contengan más restos o su importancia sea mayor por representatividad o determinación en las conclusiones.

\section{Tabla 1}

Yacimientos Paleolíticos y Epipaleolíticos situados en el sur de la provincia de Albacete

\begin{tabular}{llll}
\hline Yacimiento & $\begin{array}{l}\text { Localidad y } \\
\text { Municipio }\end{array}$ & $\begin{array}{l}\text { Periodo cronocultural } \\
\text { y dataciones }\end{array}$ & Fuente \\
\hline & Paleolítico inferior \\
\hline $\begin{array}{l}\text { La Fuente de } \\
\text { Hellín }\end{array}$ & Hellín & Achelense medio & Montes Bernárdez et al., 1984.
\end{tabular}

Paleolítico medio

\begin{tabular}{|c|c|c|c|}
\hline $\begin{array}{l}\text { La Fuente de } \\
\text { Hellín }\end{array}$ & Hellín & PM & $\begin{array}{l}\text { Montes Bernárdez y Rodríguez } \\
\text { Estrella, } 1985 .\end{array}$ \\
\hline El Pedernaloso & Isso, Hellín & Musteriense & $\begin{array}{l}\text { López Campuzano, 1993-1994; } \\
\text { Serna López, } 1999 .\end{array}$ \\
\hline $\begin{array}{l}\text { Canalizo del } \\
\text { Rayo }\end{array}$ & $\begin{array}{l}\text { Minateda, } \\
\text { Hellín }\end{array}$ & Musteriense & $\begin{array}{l}\text { Jordán Montés y López Precioso, } \\
\text { 1993; Serna López, } 1999 .\end{array}$ \\
\hline Arroyo de Isso & $\begin{array}{l}\text { Mingogil, } \\
\text { Hellín }\end{array}$ & PM & Serna López, 1999. \\
\hline Terche & $\begin{array}{l}\text { Agramón, } \\
\text { Hellín }\end{array}$ & Musteriense & $\begin{array}{l}\text { Jordán Montés y López Precioso, } \\
\text { 1993; Serna López, } 1999 .\end{array}$ \\
\hline El Navazo & $\begin{array}{l}\text { Agramón, } \\
\text { Hellín }\end{array}$ & PM & Serna López, 1999. \\
\hline El Polope & Tobarra & Musteriense de denticulados & $\begin{array}{l}\text { López Campuzano y Jordán } \\
\text { Montés, } 1995 .\end{array}$ \\
\hline $\begin{array}{l}\text { Fuente del } \\
\text { Halcón }\end{array}$ & Ayna & $\begin{array}{l}\text { Musteriense de tradición } \\
\text { Achelense }\end{array}$ & López Campuzano et al., 2003. \\
\hline $\begin{array}{l}\text { Cerro de la } \\
\text { Cantera }\end{array}$ & Ayna & $\begin{array}{l}\text { Musteriense de facies } \\
\text { Charentiense de tipo Quina }\end{array}$ & Serna López, 1995. \\
\hline $\begin{array}{l}\text { Rambla del } \\
\text { Fontanar }\end{array}$ & Alcadozo & Musteriense indeterminado & Serna López, 1990. \\
\hline
\end{tabular}




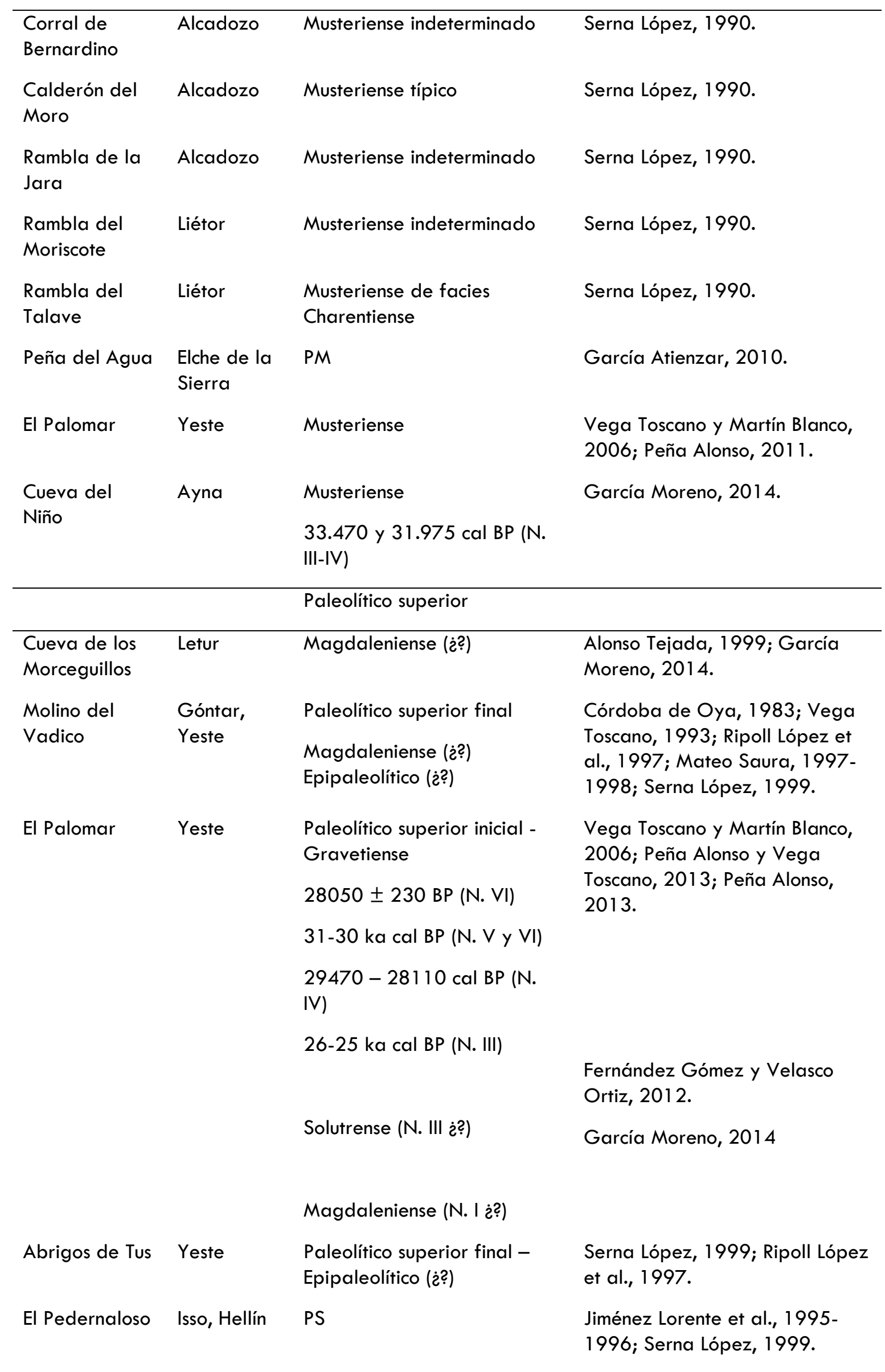




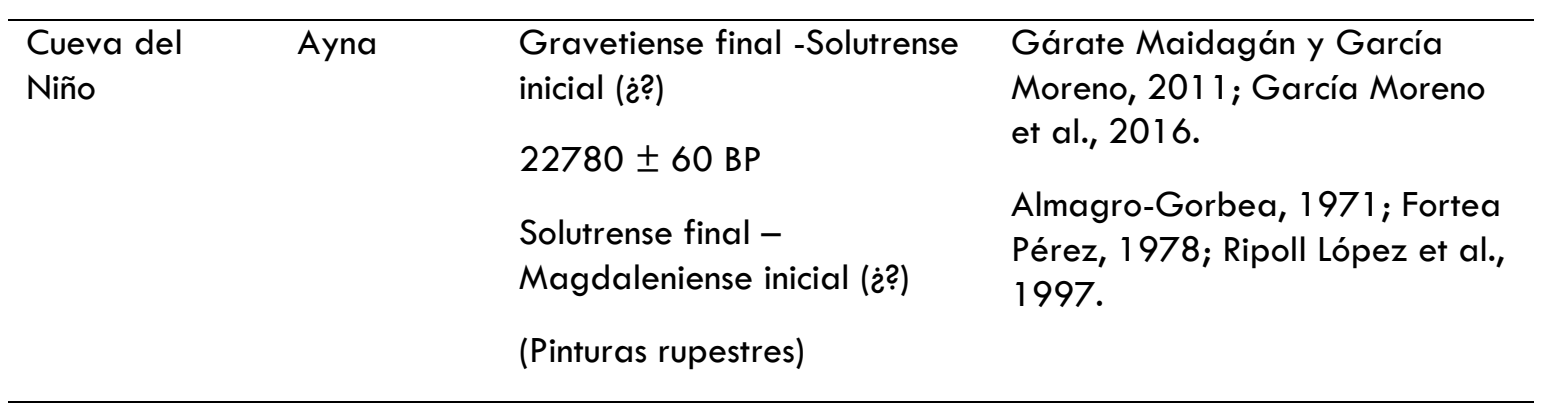

Fuente: elaboración propia. Abreviaturas: Paleolítico medio=PM, Paleolítico superior=PS.

\subsection{Paleolítico inferior}

a. La Fuente de Hellín (Hellín)

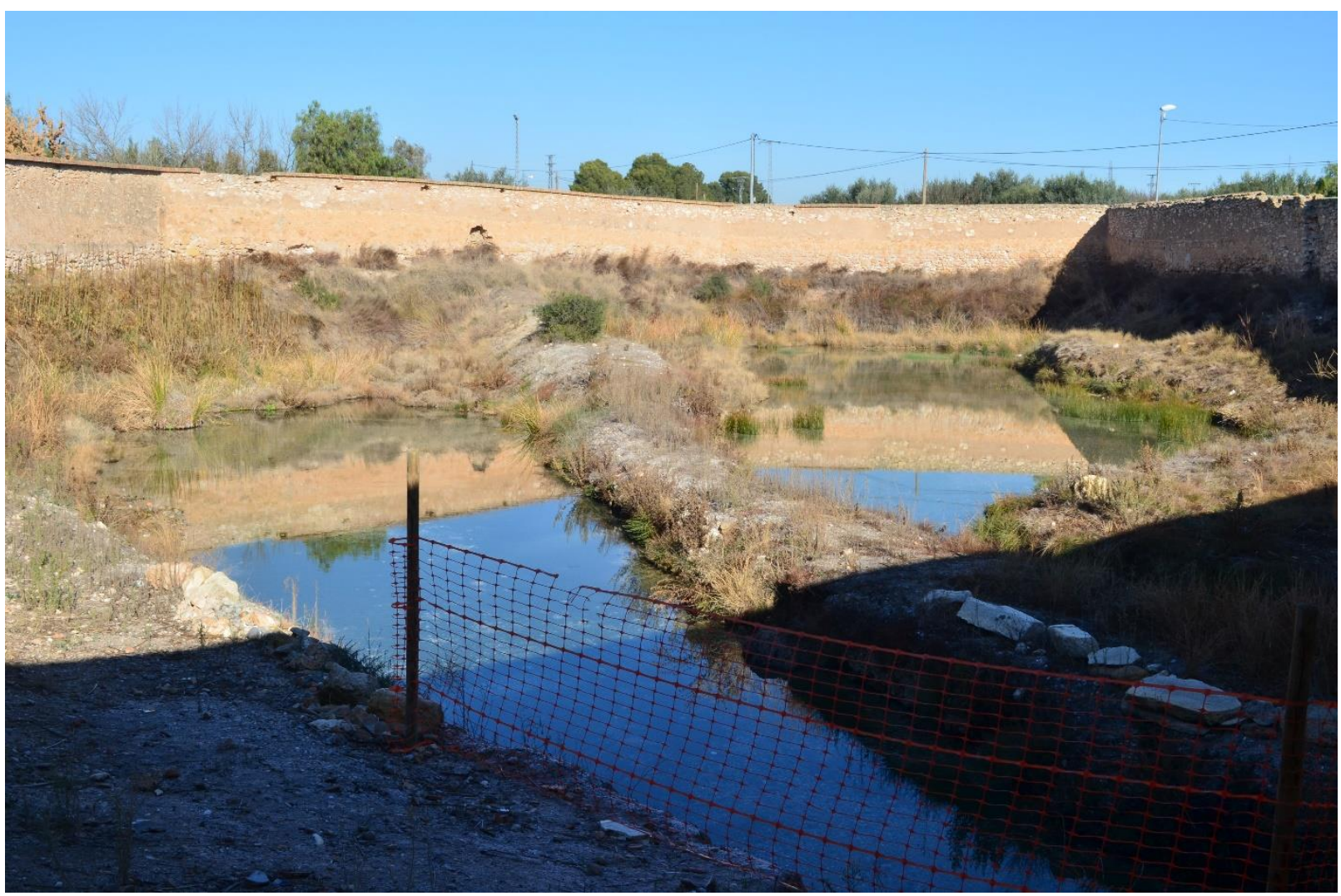

Figura 1. Estado actual del yacimiento de la Fuente de Hellín. Fuente: elaboración propia.

El Paleolítico inferior solamente tiene presencia en el sur de la provincia de Albacete en un yacimiento, la Fuente de Hellín, descubierto en el año 1963 (Serna López, 1999) y destruido totalmente durante el acondicionamiento para el regadío del surgimiento de agua en el que se encuentra, denominado "La Fuente" (Montes Bernárdez y Rodríguez Estrella, 1985) (Figura 1). En las prospecciones realizadas en los años 80 por Jordán se realizó una recogida de materiales en superficie y bajo el agua, entre los que destacan los bifaces y cantos trabajados. La materia prima predominante es la cuarcita, muy por encima del sílex, procedente de la Rambla de El Pedernaloso, un afloramiento de sílex situado a unos $6 \mathrm{~km}$ al suroeste de La Fuente, y donde también se ha localizado un yacimiento, perteneciente al Paleolítico medio (Montes Bernárdez et al., 1984). 
La extensión del yacimiento era de unos $900 \mathrm{~m}^{2}$ aproximadamente (Montes Bernárdez et al., 1984), en los que se han hallado poco más de 300 restos líticos. Entre estos restos destacan los núcleos de morfología poliédrica. La presencia de núcleos y percutores contrasta con el bajo índice de soportes, lo cual puede indicar que estamos ante una zona de talla (Montes Bernárdez et al., 1984; Montes Bernárdez y Rodríguez Estrella, 1985), aunque esta diferencia puede deberse al sesgo mencionado anteriormente en la recogida de elementos superficiales. Entre los útiles adscritos a este periodo contamos una amplia variedad de bifaces, destacando los de morfología amigdaloide y protolimandes, hendedores, cantos trabajados de un tamaño menor a los bifaces, y 20 triedros (Montes Bernárdez et al., 1984). Dentro del conjunto lítico hay restos que podrían pertenecer al Paleolítico medio, como son núcleos Levallois de extracción de lascas predeterminadas, dos fragmentos de punta Levallois de segundo orden, raederas y puntas de Tayac. Así mismo, se pudo comprobar que hay una leve presencia de útiles característicos del Paleolítico superior, como raspadores o perforadores (Montes Bernárdez y Rodríguez Estrella, 1985).

En definitiva, nos encontramos con un yacimiento con una mayoría de industria lítica perteneciente al Paleolítico inferior, con bifaces "espesos y sin regularizar", hendedores de tipo primitivo y abundantes cantos y triedros, según Montes Bernárdez, Martínez Andreu y Jordán Montés (1984), que adscribieron el sitio al Achelense medio. Sus habitantes se instalarían en las proximidades de la laguna que existía en torno al paraje de La Fuente, siendo también utilizado el sitio en el Paleolítico medio y el superior, pero de una forma mucho más puntual según atestigua la poca cantidad de restos adscritos a estos periodos.

\subsection{Paleolítico medio}

El Paleolítico medio en el sur peninsular comenzaría en los últimos momentos del Pleistoceno Medio y abarcaría los episodios de mejora climática del último interglaciar (OIS 5) y los OIS 4 (pulsación fría) y 3 , previos al endurecimiento climático vivido posteriormente en el OIS 2, durante el Paleolítico superior. Pese a las oscilaciones climáticas, dentro del periodo en el área sur mediterránea se vivió una estabilidad paleoambiental, marcada por un mantenimiento de los taxones de los mamíferos de medio y gran tamaño (Cortés Sánchez, 2005).

En cuanto al desarrollo tecnológico, que en gran parte de los yacimientos es el único marcador que nos permite realizar una datación relativa aproximada, Cortés Sánchez (2005), en su estudio general sobre el periodo en el sur de la península ibérica, indica que sería el OIS 5 el que marcaría la diferencia entre los primeros conjuntos, en los que todavía aparecen bifaces y los métodos de extracción de lascas tipo Levallois no están presentes de forma importante, y aquellos en los que el método Levallois y discoide centrípeto pasan a ser los más utilizados. Así mismo, en los momentos finales del Musteriense, la facies de denticulados sería la predominante en la mayoría de asentamientos.

\section{a. El Pedernaloso (Isso, Hellín)}

Este yacimiento se dispone a lo largo de la Rambla de El Pedernaloso (Jiménez Lorente et al., 1995-1996), atravesada por la carretera comarcal 3212 que une Hellín con Elche de la Sierra, pasando por Isso (Figura 2). Esta rambla se encuentra en las proximidades de la pedanía de Isso, partiendo de la base de un pequeño monte encima del cual se halla actualmente la Ermita del Pedernaloso, a unos $3 \mathrm{~km}$ de la población, y dirige sus aguas hasta el río Mundo (Serna López, 
1999). Está ubicado en un lugar en el que los afloramientos de sílex son ricos (López Campuzano, 1993-1994) y que ha servido como lugar de aprovisionamiento de esta materia prima para los habitantes de otros yacimientos.

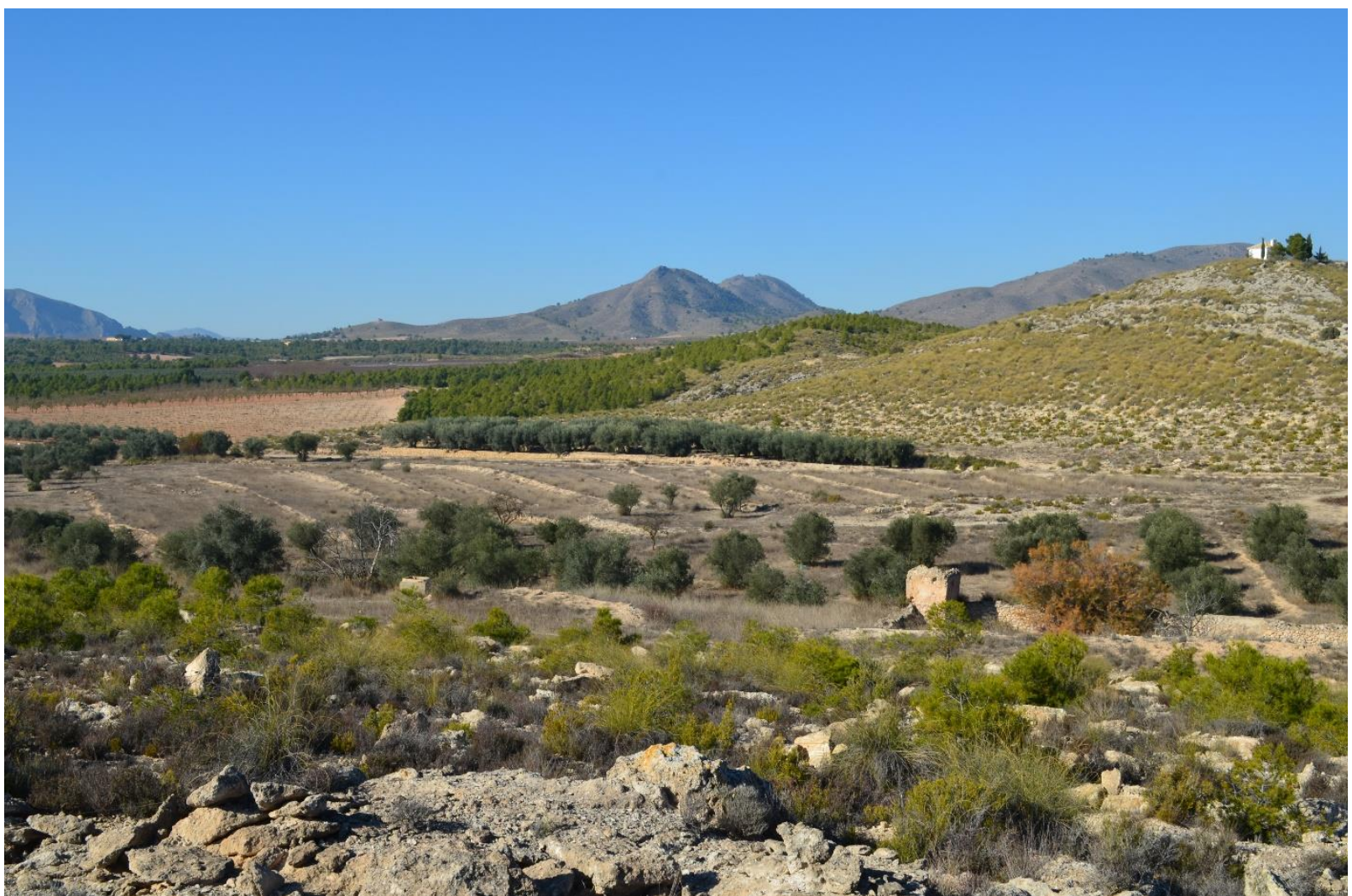

Figura 2. Cabecera de la Rambla del Pedernaloso, donde se ubicaría el asentamiento inicial. Fuente: elaboración propia.

En este sitio se llevaron a cabo dos campañas de excavación, durante 1990 y 1991, aun así, el hallazgo de materiales desde la cabecera de la rambla podría significar que estos están en posición secundaria. En 1990 se realizó un sondeo para comprobar la estratigrafía del yacimiento, en un talud formado por la acción hídrica de la rambla en un margen de la misma. El sondeo constaba de $14 \mathrm{~m}^{2}$ de superficie y $3 \mathrm{~m}$ de profundidad. Los arqueólogos encargados del estudio distinguieron ocho estratos geológicos diferenciados (Serna López, 1999). En 1991, según Serna López (1999) se abrieron dos nuevos sondeos en la zona norte de la rambla. La extensión de estos es variada, uno de $16 \mathrm{~m}^{2}$ y otro de $8 \mathrm{~m}^{2}$, y una profundidad común de un metro y medio. Los materiales arqueológicos comenzaron a aparecer a partir del tercer estrato geológico. Tras la realización de ambos sondeos se comprobó que "la industria lítica, erosionada y desplazada, aflora en los estratos geológicos número 1 y 3 , el primero conglomerado compactado en una fase cálida y el segundo un depósito fluvial correspondiente a un periodo muy húmedo en el cual se dio el desplazamiento de la industria" (López Campuzano, 1993-1994, p. 8).

El número de piezas líticas recuperadas en total en este yacimiento son 1531. En contraposición con la mayoría de yacimientos del Paleolítico medio que veremos a continuación, en El Pedernaloso la materia prima predominante es el sílex, material muy presente en la propia rambla, que fue una zona de captación de recursos líticos. La talla está especialmente dirigida a la extracción de lascas, tal y como atestiguan los núcleos discoides, típicos del Musteriense, y los 
Levallois, aunque también aparecen núcleos prismáticos, bifaciales, con preparación sumaria y sobre lasca para la extracción de lascas Kombewa (Serna López, 1999). Se halló un alto índice de soportes en forma de lasca, de entre las que destacan las de morfología Levallois, con talones facetados y diedros, típicos de este método (Serna López, 1999). En cuanto a los útiles, se constata la presencia de puntas Levallois, bifaces y un índice superior de raederas, entre las que destacan las de tipo Quina, que de muescas y denticulados. Además, se han encontrado útiles característicos del Paleolítico superior, como raspadores, buriles, lascas truncadas, cuchillos de dorso y perforadores (Jiménez Lorente et al., 1995-1996; Serna López, 1999), pero en una menor proporción que los atribuidos al Paleolítico medio, al igual que en otros yacimientos similares.

En definitiva, nos encontramos con un conjunto con muy baja presencia de la técnica Levallois y la laminar, además de un mayor índice de raederas que de denticulados y muescas (López Campuzano, 1993-1994). Estas características, junto a la casi nula presencia de bifaces, llevó a los investigadores a clasificarlo como Musteriense típico (López Campuzano, 1993-1994) cronológicamente situado en el Würm inicial (Jiménez Lorente et al., 1995-1996).

\section{b. Canalizo del Rayo (Minateda, Hellín), Arroyo de Isso (Mingogil, Hellín), Terche y El Navazo (Agramón, Hellín)}

Debido a la proximidad geográfica de estas cuatro estaciones superficiales, situadas al sur del núcleo de población de Hellín, pasaremos a analizarlas de forma conjunta buscando similitudes o diferencias que nos ayuden a entender su procedencia.

El Canalizo del Rayo se sitúa en un valle, con el mismo nombre, en las proximidades de Minateda y del arroyo de Tobarra, que desemboca en el río Mundo (Serna López, 1999). Fue descubierto en 1928 por Breuil, que ya los adscribió al complejo Musteriense (Breuil, 1928; Hernández Pérez, 2002; Serna López, 1997). El yacimiento, que es el que más restos presenta de los cuatro (37), ha sido catalogado como Musteriense (Jordán Montés y López Precioso, 1993) y más concretamente como Musteriense tardío (Serna López, 1999), por la presencia de núcleos discoides y soportes de tipo Levallois.

El sitio del Arroyo de Isso está situado en una elevación del terreno en las inmediaciones de la pedanía de Mingogil, en un valle paralelo al de El Pedernaloso, también surcado por ramblas que discurren en la misma dirección. Serna, en su recopilación de 1999, ya advierte de que puede tratarse de restos que proceden de otro lugar, pues la elevación en la que se encuentran está cubierta por sedimento trasladado para el acondicionamiento de bancales. Presenta solamente cuatro piezas, pero dos de ellas son puntas de tipo Levallois (Serna López, 1999), lo cual nos indica la aplicación de este método en esta zona.

Terche se sitúa en una ladera próxima a una pequeña llanura entre las colinas de las que toma el nombre el yacimiento, en la sierra de la Cabeza Llana, muy próximo al curso medio del río Mundo. Los materiales encontrados se componen de algunas raederas y dos puntas de cuarcita, que por su morfología y retoque se clasifican como musterienses (Jordán Montés y López Precioso, 1993; Serna López, 1999).

Finalmente, contamos con otro hallazgo superficial situado en una llanura entre la sierra del Candil y las Lomas de la Cañada del Toril, al noreste del pantano de Camarillas, en una rambla 
que dirige su caudal hacia el río Mundo. Los restos encontrados son escasos, destacando dos puntas de sílex retocadas, una de las cuales "parece tener un pedúnculo proximal formado por dos amplias muescas" según Jordán Montés (Serna López, 1999, p. 59).

En todas estas estaciones la cuarcita es la materia prima más utilizada y cuentan con puntas líticas entre su registro, aunque solamente los dos primeros presentan restos de aplicación del método Levallois. La escasez de restos nos impide aproximarnos más a una interpretación del área.

\section{c. El Polope (Tobarra)}

Este yacimiento se ubica en el municipio de Tobarra, en los alrededores de una laguna, ya desaparecida, existente durante el Pleistoceno superior, a unos $12 \mathrm{~km}$ al norte de El Pedernaloso, el cual podría haber servido de lugar de aprovisionamiento de sílex (López Campuzano, 19931994) y a $4 \mathrm{~km}$ al oeste de Tobarra, en un valle entre la sierra de Abenuj y la de Montesinos (López Campuzano y Jordán Montés, 1995).
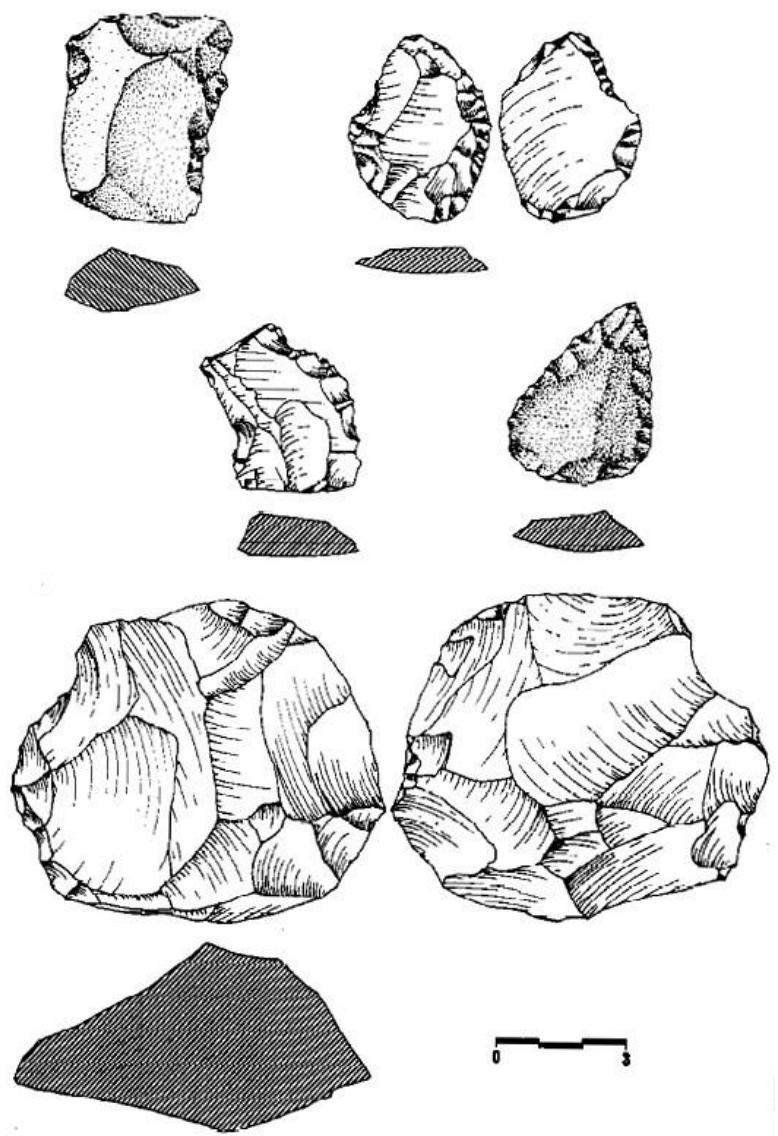

Figura 3. Industria lítica del yacimiento de El Polope. Tres raederas de diversa morfología, una punta Levallois y un núcleo discoide. Fuente: López Campuzano y Jordán Montés, 1995, p. 35.

Las piezas líticas pertenecientes a este yacimiento fueron recogidas durante una prospección (López Campuzano y Jordán Montés, 1995), en la que se constató un empleo predominante de cuarcitas locales, aunque el nivel de sílex es elevado (alrededor del $20 \%$ ) y procede del afloramiento de la rambla de El Pedernaloso (López Campuzano, 1993-1994). Se recuperaron 170 piezas, entre las que predominan los soportes en forma de lasca, y hay una relativa presencia de núcleos discoides, y útiles sobre núcleo, como un bifaz y cuatro cantos trabajados unifaciales (López Campuzano y Jordán Montés, 1995). El sitio presenta un índice más elevado 
de muescas y denticulados que de raederas, aunque estas también tienen una presencia importante, por lo que dificulta la adscripción del conjunto al Musteriense de Denticulados (López Campuzano y Jordán Montés, 1995) (Figura 3). López Campuzano indica a este respecto que la proporcionalidad de denticulados y muescas frente a la de raederas dependería de la materia prima que se importase desde El Pedernaloso, debido a que estas últimas se fabricaban sobre lascas de sílex (López Campuzano, 1993-1994).

\section{d. Fuente del Halcón (Ayna)}

Este hallazgo superficial se encuentra muy próximo a la Cueva del Niño (Ayna), de la que hablaremos más adelante, localizado en el paraje de la Fuente del Halcón, del cual toma el nombre, llamado así por la presencia de un surgimiento natural de agua, entre la Muela Grande y el Barranco del Infierno (López Campuzano et al., 2003).

Se localizaron solamente 13 piezas de nódulos de cuarcita de origen local (García Moreno, 2014). La mayoría de los restos corresponden a núcleos, preparados para la extracción de lascas con "nervadura central y de dorso natural o de lascas sin córtex de tipología levallois" y lascas de primer y segundo orden (López Campuzano et al., 2003, p. 25). Al ser los esquemas de reducción utilizados el discoide-Levallois y el pseudoprismático, se aproxima a la tecnología aplicada en el Paleolítico medio y López Campuzano y sus colaboradores (2003) lo clasifican como Musteriense de tradición Achelense. La variabilidad tecnológica podría ser explicada por la utilización del sitio como refugio estacional de diversos grupos en un periodo de tiempo amplio (López Campuzano et al., 2003).

\section{e. Cerro de la Cantera (Ayna)}

En la ladera del Cerro de la Cantera, en el término municipal de Ayna, se encuentra el yacimiento homónimo, relativamente próximo también a la Cueva del Niño. Se localizaron 28 piezas en superficie, entre las que destacan una lasca Levallois típica y una amplia proporción de raederas, que suponen casi el $20 \%$ total del conjunto, entre las que hay de tipo Quina. La adscripción dada a este conjunto es la de Musteriense de tipo Quina (Serna López, 1995), debido a la poca presencia de talla Levallois, el alto número de raederas y la presencia de este tipo de retoque.

\section{f. Rambla del Fontanar, Corral de Bernardino, Rambla de la Jara y Calderón del Moro (Alcadozo)}

En el término municipal de Alcadozo, colindante con el de Ayna, se han hallado una serie de estaciones paleolíticas en superficie. Estos hallazgos son puntuales y los materiales recogidos escasos (ver Tabla 2). Los cuatro coinciden en la materia prima, la cuarcita, aunque debemos recordar que al ser yacimientos en posición secundaria existe un sesgo en el traslado y la recogida de los restos.

Los dos primeros yacimientos presentan restos de la aplicación del método Levallois, ya sea en núcleos o en soportes y útiles (Serna López, 1999). En Rambla de la Jara, el hecho de que solamente se hayan hallado dos piezas (Serna López, 1999) nos impide extraer más información. Estos tres sitios fueron catalogados como Musteriense indeterminado.

Caso diferente encontramos en el Calderón del Moro. Este yacimiento se encuentra en una elevación del terreno situada a $4 \mathrm{~km}$ de Alcadozo, próximo a la carretera que une esta localidad 
con Santa Ana. En este caso se localizaron 42 piezas, con una mayor presencia de sílex que en los anteriores, habiendo 8 piezas de esta materia prima. Entre los restos también contamos con núcleos y lascas de tipo Levallois, además de un elevado índice de raederas dentro del limitado conjunto. Se clasificó como Musteriense típico debido a estas características (Serna López, 1990).

\section{g. Rambla de Moriscote (Moriscote, Liétor) y Rambla del Talave (Liétor)}

Estas dos estaciones al aire libre tienen características similares a las situadas en el municipio de Alcadozo, y podrían enmarcarse dentro de un mismo conjunto debido a la cercanía territorial. Destacamos el hecho de que en la Rambla del Talave, López Serna (1999) hallase las características de la talla Levallois en el conjunto y además numerosos soportes de lasca y un elevado índice de raederas, para lo limitado de los restos hallados (41). Este hecho llevó al autor a encuadrarlo dentro del Musteriense de facies Charentiense, aunque estas mismas características se repiten en otras estaciones que se han considerado como pertenecientes al tecnocomplejo Musteriense pero indeterminadas.

\section{h. Peña del Agua (Elche de la Sierra)}

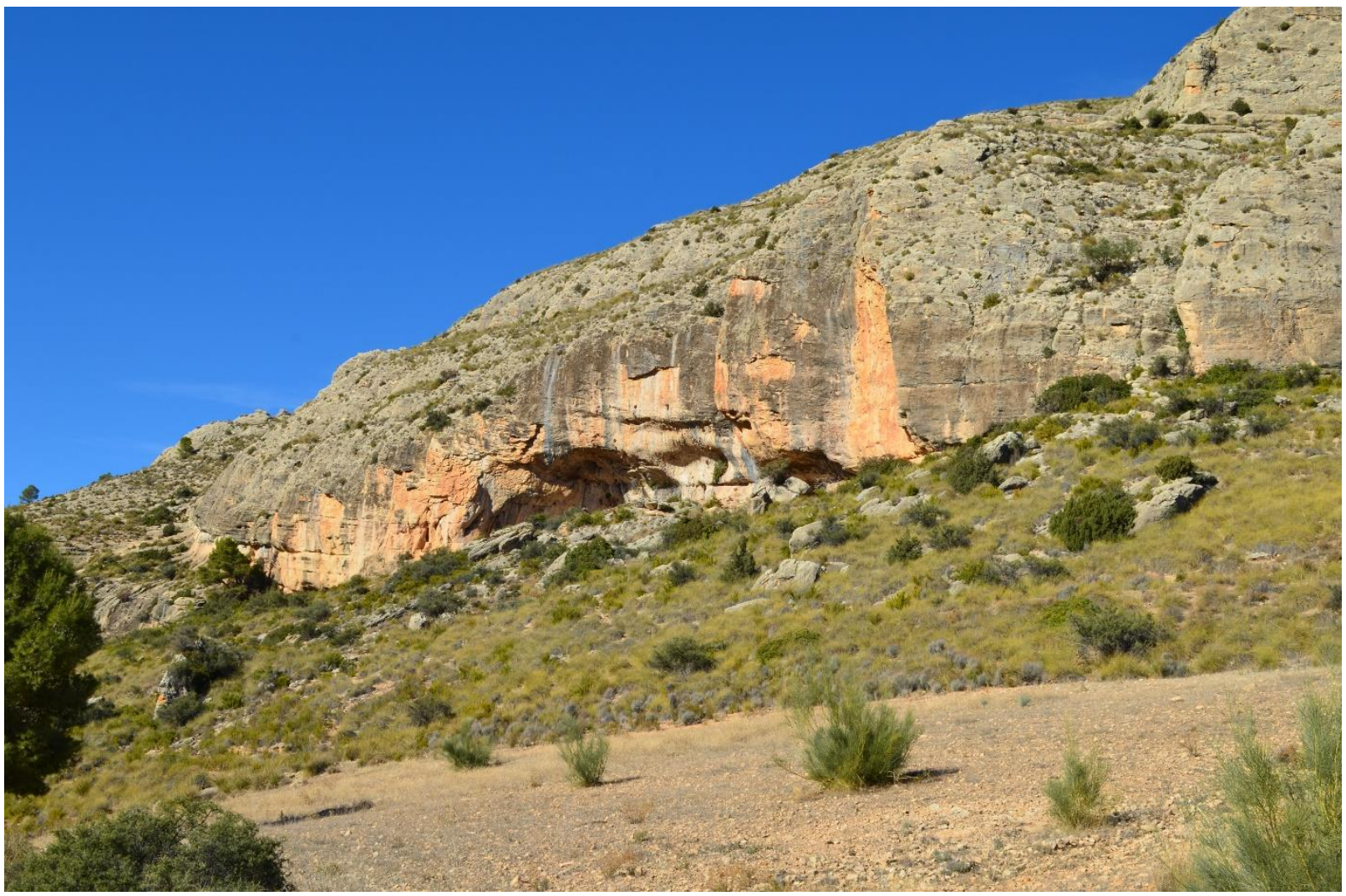

Figura 4. Abrigos de la Peña del Agua y ladera en la que se encuentran los restos líticos. Fuente: elaboración propia.

En este caso nos encontramos en el municipio de Elche de la Sierra, en una elevación del terreno que está situada en la parte sur de la Peña de San Blas, llamada Peña del Agua, de la cual toma su nombre el yacimiento. En la vertiente sur de este monte se abren una serie de abrigos con poco sedimento conservado, por lo que los restos líticos hallados se encuentran dispersos en la ladera y en las terrazas abandonadas en las que termina la misma (Figura 4). 
El conjunto de materiales recogidos en este lugar abarca una gran diversidad cronológica, de entre los que se hallan restos líticos del Paleolítico medio (García Atiénzar, 2010). No contamos con más datos de esta estación.

En último lugar, y volviendo a destacar la importancia del estudio realizado en 1999 por Serna López sobre el Paleolítico medio en la cuenca del río Mundo, extraemos del mismo una clasificación realizada por este autor que no se basa en localizaciones concretas sino en áreas más extensas que reúnen varios hallazgos con una tecnología y un ambiente común. Algunos de los yacimientos descritos anteriormente se circunscriben a alguna de estas tres áreas, pero los hemos descrito aparte debido a que tienen entidad propia. Así mismo hemos seguido su metodología de análisis a la hora de realizar las agrupaciones de pequeños hallazgos realizados en áreas concretas.

\section{i. Río Mundo A}

En primer lugar, se contempla el área de ocupación de Río Mundo A. Esta se extiende por el territorio entre Alcadozo y Liétor, en el norte de la cuenca media del río Mundo, recorrido por numerosas ramblas que dirigen su caudal hacia el embalse del Talave. Los hallazgos realizados en esta área son 237 piezas, la mayoría de cuarcita, destacando la presencia de núcleos, discoides y Levallois, y lascas Levallois, de tercer orden y con talones facetados y diedros. En cuanto a los útiles, destacan las raederas, y dentro de ellas las de tipo Quina; también un elevado número de denticulados y muescas, aunque en una proporción menor; y cantos trabajados, triedros, un hendedor y protobifaz espeso amigdaloide que nos indican el sustrato antiguo que pervive en esta área. Al igual que en otros casos, hay piezas características del Paleolítico superior, como raspadores, perforadores y lascas truncadas (Serna López, 1999). El investigador Serna López (1999) indica que nos encontramos con un conjunto no Levallois, aunque hay restos del uso de esta tecnología, y lo adscribe al tecnocomplejo Musteriense, con presencia de tipos Quina y un predominio de raederas (Figura 5). Nosotros tratamos esta afirmación con reservas, ya que la presencia del método Levallois está constatada y la proporción es lo suficientemente grande como para tenerlo en consideración.
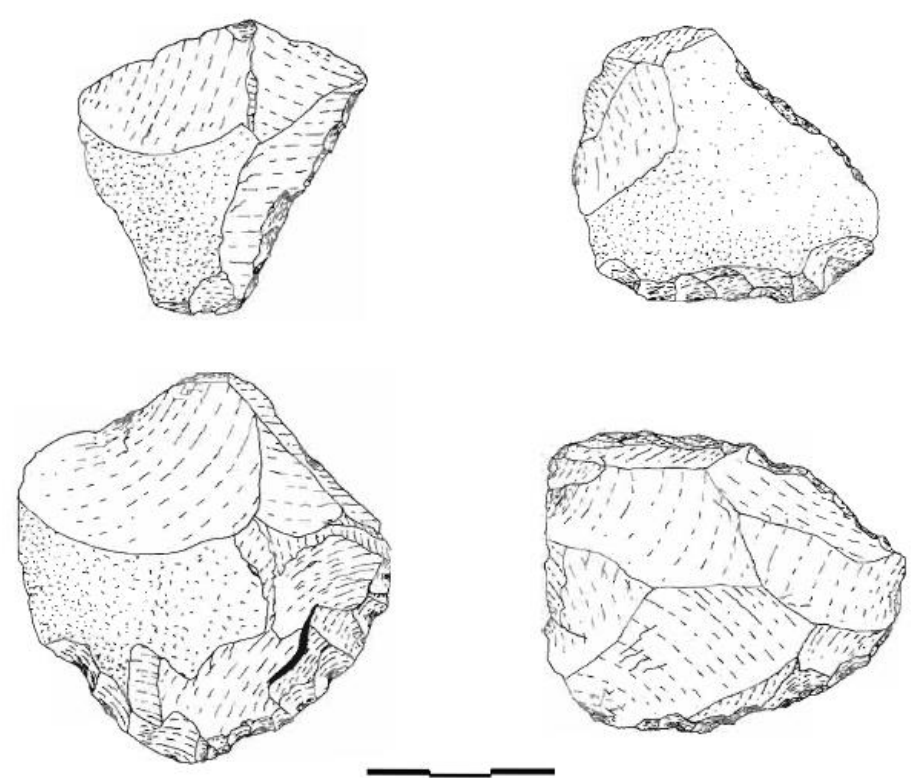

Figura 5. Industria lítica del área Río Mundo A. Raederas. Fuente: Serna López, 1999, p. 67. 


\section{j. Río Mundo B}

Al este de la anterior, se sitúa la segunda área de ocupación señalada por Serna López (1999). Esta se circunscribe al municipio de Ayna, en ambos márgenes del río Mundo, con un medio caracterizado por pendientes escarpadas, sobre todo en la zona más próxima al cauce del río. En esta zona se localizaron 117 piezas. Al igual que en Río Mundo A, destaca la gran cantidad de soportes en forma de lasca, que componen casi el $50 \%$ del conjunto. El método Levallois continúa estando presente en la zona, aunque la variabilidad en los núcleos es mayor, apareciendo también bifaciales, prismáticos, discoides, poliédricos y planos en similares proporciones. Así mismo se mantiene el uso del retoque tipo Quina en la realización de raederas y se utilizan las lascas preferentes del método Levallois para la confección de puntas. Sin embargo, el nivel de elementos de sustrato desciende, con la presencia de un canto trabajado bifacial y un protobifaz amigdaloide. Una vez más, se hallaron útiles representantes del Paleolítico superior, como un cuchillo de dorso y un buril (Serna López, 1999) (Figura 6). Serna López identifica el conjunto de igual modo que el anterior: Musteriense de tipo Quina, aunque nosotros continuamos reseñando la importancia de la presencia del método Levallois como indicador de pervivencia de esta tecnología.
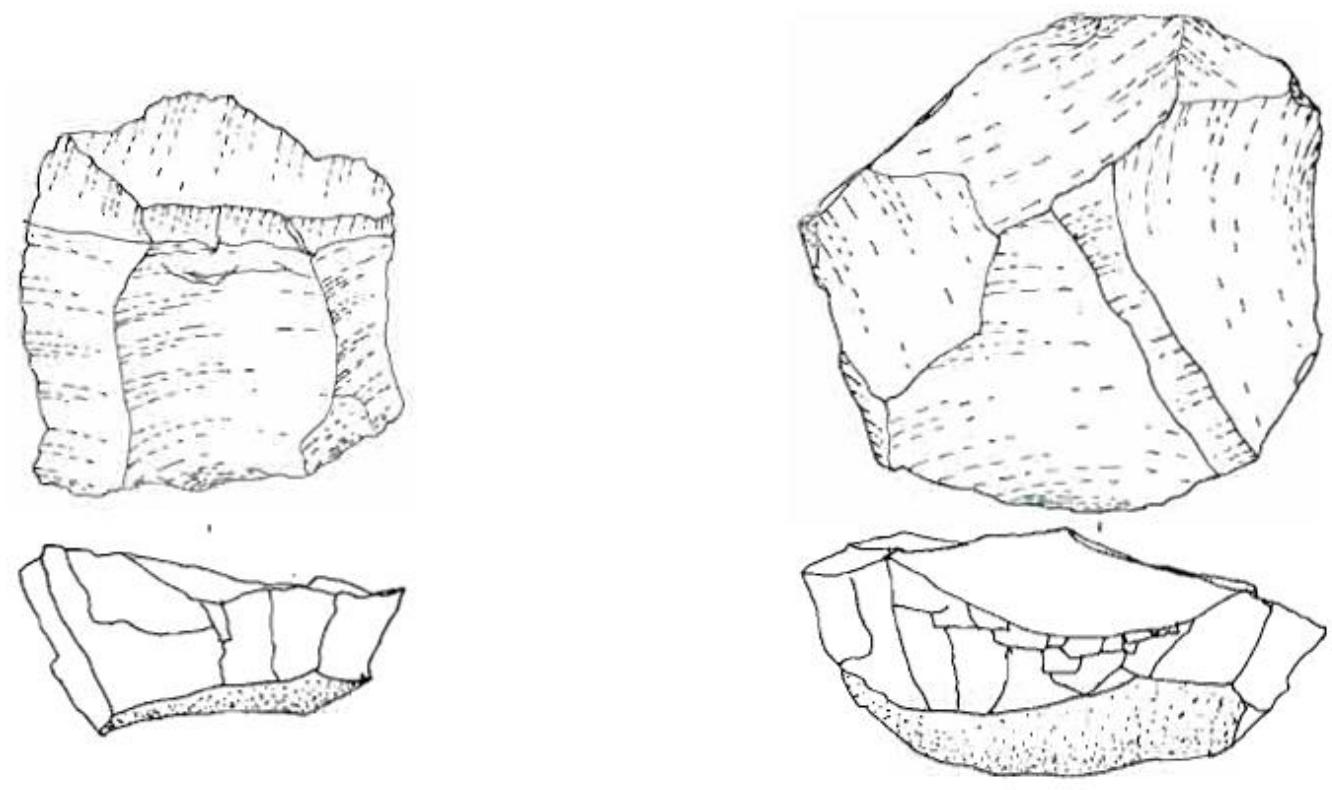

Figura 6. Industria lítica del área Río Mundo B. Núcleos. Fuente: Serna López, 1999, p. 79.

\section{k. Río Mundo C}

Por último, se describe un área de ocupación en el curso alto del río Mundo, en los municipios de Molinicos y Bogarra, donde predominan las altas elevaciones del terreno y con un buen número de ramblas que dirigen su cauce hacia el río (Serna López, 1999). Se encontraron 121 piezas, con un claro predominio de los soportes en forma de lasca, entre las que aparecen las de tipo Levallois. Estos soportes están relacionados con un amplio número de núcleos, más de un $18 \%$ del total, discoides en su mayoría, con presencia de Levallois (Serna López, 1999). Raederas y muescas y denticulados aparecen en la misma proporción, lo cual hace que no nos decantemos por la utilización de este indicador para la adscripción del conjunto. En el Paleolítico superior 
continúan apareciendo raspadores, buriles y lascas truncadas (Serna López, 1999). Serna López (1999) concluye que estamos de nuevo ante un conjunto no Levallois, pero en este caso con un índice de raederas más bajo que los anteriores, mientras que las muestras y denticulados elevan su proporción en comparación con las otras zonas.

Tabla 2

Restos líticos recuperados en los yacimientos y zonas de hallazgos en superficie adscritos al Paleolítico medio

\begin{tabular}{|c|c|c|c|c|c|c|c|c|c|c|c|c|}
\hline Yacimiento & $\begin{array}{l}M \\
L\end{array}$ & Nu & TN & $R$ & $\begin{array}{l}M / \\
D\end{array}$ & $\begin{array}{l}T \\
Q\end{array}$ & $\begin{array}{l}P \\
\text { Le }\end{array}$ & $\begin{array}{l}P \\
M\end{array}$ & $\begin{array}{l}B \\
P\end{array}$ & $\mathrm{CT}$ & MP & Fuente \\
\hline $\begin{array}{l}\text { La Fuente de } \\
\text { Hellín }\end{array}$ & $S$ & 10 & $\mathrm{~L}$ & 12 & $x$ & $\mathrm{~N}$ & 2 & & & & $C$ & $\begin{array}{l}\text { Montes } \\
\text { Bernárdez y } \\
\text { Rodríguez } \\
\text { Estrella, } 1985 .\end{array}$ \\
\hline $\begin{array}{l}\text { El } \\
\text { Pedernaloso }\end{array}$ & $S$ & 54 & $D / L$ & 34 & $\begin{array}{l}8 / \\
13\end{array}$ & $S$ & 4 & & 2 & & $F$ & $\begin{array}{l}\text { Serna López, } \\
1999 .\end{array}$ \\
\hline $\begin{array}{l}\text { Canalizo del } \\
\text { Rayo }\end{array}$ & $S$ & 13 & $\mathrm{D} / \mathrm{Pr}$ & & & $N$ & $x$ & & & & C & $\begin{array}{l}\text { Serna López, } \\
1999 .\end{array}$ \\
\hline $\begin{array}{l}\text { Arroyo de } \\
\text { Isso }\end{array}$ & $S$ & & & & & $N$ & 2 & & & & $F$ & $\begin{array}{l}\text { Serna López, } \\
1999 .\end{array}$ \\
\hline Terche & $\mathrm{N}$ & & & 2 & & $N$ & & 2 & & & C & $\begin{array}{l}\text { Jordán Montés } \\
\text { y López } \\
\text { Precioso, } 1993 .\end{array}$ \\
\hline El Navazo & $\mathrm{N}$ & & & & & $N$ & & 1 & & & $F$ & $\begin{array}{l}\text { Serna López, } \\
1999 .\end{array}$ \\
\hline El Polope & $N$ & 20 & $D$ & 23 & 64 & $N$ & & & 1 & 4 & C & $\begin{array}{l}\text { López } \\
\text { Campuzano, } \\
\text { 1993-1994; } \\
\text { López } \\
\text { Campuzano y } \\
\text { Jordán Montés, } \\
1995 .\end{array}$ \\
\hline $\begin{array}{l}\text { Fuente del } \\
\text { Halcón }\end{array}$ & $S$ & $x$ & & & & $N$ & & & & & C & $\begin{array}{l}\text { López } \\
\text { Campuzano et } \\
\text { al., 2003; } \\
\text { García } \\
\text { Moreno, } 2014 .\end{array}$ \\
\hline $\begin{array}{l}\text { Cueva del } \\
\text { Niño }\end{array}$ & $S$ & & $\mathrm{Dc} / \mathrm{L}$ & 5 & $0 / 1$ & $S$ & & 1 & & & C & $\begin{array}{l}\text { García Moreno } \\
\text { et al., } 2014\end{array}$ \\
\hline $\begin{array}{l}\text { Cerro de la } \\
\text { Cantera }\end{array}$ & $S$ & 6 & L & 5 & $1 / 0$ & $S$ & & & & & C & $\begin{array}{l}\text { Serna López, } \\
1995 .\end{array}$ \\
\hline $\begin{array}{l}\text { Rambla del } \\
\text { Fontanar }\end{array}$ & $S$ & 2 & $L$ & 2 & & $N$ & & & & & C & $\begin{array}{l}\text { Serna López, } \\
1990 .\end{array}$ \\
\hline
\end{tabular}




\begin{tabular}{|c|c|c|c|c|c|c|c|c|c|c|c|c|}
\hline $\begin{array}{l}\text { Corral de } \\
\text { Bernardino }\end{array}$ & $S$ & 1 & L & 2 & $1 / 0$ & $N$ & & & & & $C$ & $\begin{array}{l}\text { Serna López, } \\
1990 .\end{array}$ \\
\hline $\begin{array}{l}\text { Calderón del } \\
\text { Moro }\end{array}$ & $S$ & 4 & L & 6 & $2 / 0$ & $N$ & & & & 1 & $C$ & $\begin{array}{l}\text { Serna López, } \\
1990 .\end{array}$ \\
\hline $\begin{array}{l}\text { Rambla de la } \\
\text { Jara }\end{array}$ & $\mathrm{N}$ & 1 & & & & $N$ & & & & & $C$ & $\begin{array}{l}\text { Serna López, } \\
1990 .\end{array}$ \\
\hline $\begin{array}{l}\text { Rambla del } \\
\text { Moriscote }\end{array}$ & $N$ & & & 1 & & $N$ & & & & & $C$ & $\begin{array}{l}\text { Serna López, } \\
1990 .\end{array}$ \\
\hline $\begin{array}{l}\text { Rambla del } \\
\text { Talave }\end{array}$ & $S$ & 3 & $\mathrm{~L} / \mathrm{P}$ & 5 & & $\mathrm{~N}$ & & & & 1 & $C$ & $\begin{array}{l}\text { Serna López, } \\
1990 .\end{array}$ \\
\hline El Palomar & $S$ & - & $\begin{array}{l}L / D \\
B\end{array}$ & - & - & $\mathrm{N}$ & & & & & $C$ & $\begin{array}{l}\text { Peña Alonso, } \\
2011 \text {; Peña } \\
\text { Alonso y Vega } \\
\text { Toscano, } 2013 .\end{array}$ \\
\hline Río Mundo A & $S$ & 42 & $D / L$ & $x$ & 11 & $S$ & & & 1 & 6 & $\mathrm{C}$ & $\begin{array}{l}\text { Serna López, } \\
1999 .\end{array}$ \\
\hline Río Mundo B & $S$ & 28 & $\begin{array}{l}\mathrm{Pl} / \mathrm{L} \\
\mathrm{B} / \mathrm{Pr} \\
\mathrm{D} / \mathrm{Po}\end{array}$ & 10 & $1 / 2$ & $S$ & 1 & 1 & 1 & 1 & $\mathrm{C}$ & $\begin{array}{l}\text { Serna López, } \\
1999 .\end{array}$ \\
\hline Río Mundo C & $S$ & 22 & $\begin{array}{l}\mathrm{D} / \mathrm{L} \\
\mathrm{Pr} / \mathrm{PoB}\end{array}$ & 6 & 6 & $\mathrm{~N}$ & & & & 4 & C & $\begin{array}{l}\text { Serna López, } \\
1999 .\end{array}$ \\
\hline
\end{tabular}

Fuente: Elaboración propia. Abreviaturas: Método Levallois=ML; Núcleos=Nu; Tipología de Núcleos=TN; Raederas=R; Muescas/Denticulados=M/D; Tipo Quina=TQ; Puntas Levallois=Ple; Puntas Musterienses=PM; Bifaz o Protobifaz $=\mathrm{BP}$; Cantos Trabajados $=\mathrm{CT}$; Materia Prima Preferente $=M P$; Levallois $=\mathrm{L}$; Discoide $=\mathrm{D}$; Discoide cordal $=\mathrm{Dc}$; Prismático $=\mathrm{Pr} ;$ Poliédrico $=\mathrm{Po} ;$ Bifacial $=\mathrm{B} ; \mathrm{Plano}=\mathrm{Pl} ;$ Cuarcita $=\mathrm{C} ;$ Sílex $=\mathrm{F} ; \mathrm{Sí}=\mathrm{S} ; \mathrm{No}=\mathrm{N} ; \mathrm{X}=$ Presencia sin datos concretos de número.

\subsection{Paleolítico superior}

La desaparición de los neandertales y la llegada de los Humanos Anatómicamente Modernos (en adelante HAM) genera todavía, a día de hoy, una gran controversia entre la comunidad científica. Por un lado, se debate sobre la pervivencia de los neandertales hasta fechas tardías en el sur de la península ibérica y en Portugal, y por otro sobre las "industrias de transición" que marcan el paso de la presencia de los neandertales a la llegada de los HAM, como transición o como cambio radical.

Una de las hipótesis propuestas ha sido la de la "Frontera del Ebro", planteada por Zilhão (1993; 2000; 2006 y 2009) y junto con otros investigadores (Zilhão y d'Errico, 1999; Zilhão y Pettitt, 2006; Zilhão et al., 2015). En ella se plantea que "the 'Ebro Frontier' model hypothesizes that (a) in Valencia, Murcia, Andalusia, Gibraltar, the Mesetan hinterland, and Portugal, the corresponding chronostratigraphic slot is occupied by a late-persisting Mousterian and (b) the pattern is explained by the major biogeographical divide that the Ebro basin would have been at that time" (Zilhão et al., 2017, p. 2). Esta teoría ha sido puesta en duda por algunos autores que argumentan, sobre todo, tres razones: la imprecisión de algunas dataciones realizadas por radiocarbono para unas cronologías en las que esta técnica comienza a generar fallos, la carencia de restos óseos vinculados a las industrias de transición, así como la ambigüedad en la 
definición y análisis de esos conjuntos, y la complejidad y alteración de algunas estratigrafías tomadas como base para estudiar este proceso (Straus, 2018; Wood et al., 2013).

Una reflexión profunda acerca del tema es la realizada por Mayor Benadero (2017), en la que el autor se decanta por concluir que, con los datos existentes actualmente, la pervivencia de los neandertales más allá del 45.000 BP y los procesos de extinción de los neandertales y llegada de los HAM debieron ser independientes. Posteriormente a su publicación, Zilhão y su equipo volvieron a reafirmar los argumentos de la tesis contraria con nuevas dataciones, realizadas mediante radiocarbono y termoluminiscencia en los yacimientos de Cueva Antón y el Abrigo de La Boja (Mula, Murcia), que contrastan algunas de las cronologías rechazadas por los autores citados anteriormente por tacharlas de imprecisas, y nuevos conjuntos líticos (Zilhão et al., 2017). En este caso, se vuelve a apoyar la pervivencia de los neandertales, la transición de los tecnocomplejos del Paleolítico medio hacia el Paleolítico superior y la expansión de los HAM entre los años 42.000 y 37.000 , junto con la teoría de la "Frontera del Ebro". Entre los yacimientos que analizaremos a continuación encontramos datos que podrían apoyar la propuesta de Zilhão, aunque debemos tomarlos con precaución.

En lo que respecta al Paleolítico superior, situado entre el 38.000 y el 10.000 BP (Fullola Pericot et al., 2005), se encuentra dividido en cuatro subperiodos: Auriñaciense, Gravetiense, Solutrense y Magdaleniense. Durante su desarrollo se dieron momentos de gran variabilidad climática, con los eventos Heinrich 3 y 2, el episodio OIS 2 y el Último Máximo Glaciar, que generaron grandes cambios económicos y culturales durante todo el periodo (Straus, 2018). Estas oscilaciones se tradujeron en un clima más frío, que generó una reserva climática en la zona sur mediterránea, y más árido en los momentos más duros, en el Solutrense. La adaptación a estas condiciones y a los cambios paleoambientales derivados de las mismas, junto con los avances tecnológicos, provocaron una sucesión de cambios, con la aparición de tipos o técnicas características para momentos concretos.

Durante el Auriñaciense cobra especial importancia la industria ósea y la introducción mayoritaria de la talla laminar, que protagonizaría todo el Paleolítico superior. El Gravetiense, momento de estabilización, está presente en nuestra zona de estudio, quizás por la gran expansión demográfica que tuvo lugar en un momento de estabilidad paleoclimática, previa a los eventos del Último Máximo Glaciar, que en el Solutrense generaron grandes cambios, sobre todo con la posible aparición del arco (Muñoz lbáñez, 1999; Muñoz lbáñez et al., 2012) y la estabilización de la captación de recursos (Fullola Pericot et al., 2005). La mejora climática del Tardiglaciar durante el Magdaleniense provocaría la microlitización de los elementos líticos y el aumento de los óseos, adaptados a los nuevos escenarios de caza y captación de otros recursos, con una mayor especialización y una reducción del tamaño de la fauna (Straus, 2018).

En cuanto a la evolución demográfica, se da un lento avance desde los momentos iniciales del Auriñaciense, con ocupaciones escasas en la zona sur, que se intensificarían durante el Gravetiense, creando los núcleos de la zona valenciana y almeriense. Estas áreas mantendrían la presencia de las poblaciones del Paleolítico superior, durante el Solutrense, cuando se intensificaría el uso de los yacimientos y se hallan secuencias nuevas. Finalmente, en el Tardiglaciar y en los inicios del Holoceno aumenta considerablemente la demografía, abarcando espacios que anteriormente era habitados de forma excepcional y se estabilizan las ocupaciones en torno a redes de captación de recursos (Sánchez-Martínez, 2019). 


\section{a. La Cueva de los Morciguillos o Morceguillos (Letur)}

Hallazgo publicado Cuadrado Díaz (1947), localizado en el término municipal de Letur, en la cuenca de uno de los afluentes del río Segura, el Taibilla. Les atribuye una posible adscripción magdaleniense a algunos de los materiales óseos, quizás punzones, encontrados en la cueva, aunque su localización junto a cerámicas neolíticas hace dudosa esta afirmación (Alonso Tejada, 1999; García Moreno, 2014).

\section{b. El Molino del Vadico (Gontar, Yeste)}

Este yacimiento se localiza en el tramo medio de la cuenca del río Zumeta, afluente del río Segura en su vertiente derecha. En este punto el río forma un valle profundo en el que se abre la cavidad, a pocos kilómetros de su desembocadura en el río Segura, en forma de abrigo con $14 \mathrm{~m}$ de boca y $4 \mathrm{~m}$ de profundidad. El relleno del yacimiento fue seccionado por las obras de ampliación de una pista forestal, que dejaron al descubierto parte de la estratigrafía del yacimiento y fue descubierto por Vega Toscano (Serna López, 1999; Vega Toscano, 1993).

Entre 1987 y 1991 se llevaron a cabo las excavaciones en este yacimiento en las cuales se consiguió distinguir una estratigrafía de 22 niveles (Vega Toscano, 1993), con una profundidad de 2,10 m de sedimento. Estos 22 niveles están organizados en dos horizontes, el inferior con los niveles B 1-D6 que pertenecen a un Paleolítico superior-Epipaleolítico, y los niveles superiores que son del Neolítico antiguo o medio. El horizonte inferior contiene industria de tipo microlaminar, con raspadores, dorsos y alguna microgravette. Truncaduras, buriles y denticulados también atestiguan su presencia, así como los núcleos, percutores y restos de talla, que indican una posible talla in situ. En este yacimiento se cuenta con industria ósea, representada por conchas perforadas de adorno personal y también fauna, destacando la cabra salvaje, de la que se hallan restos de todas las regiones esqueléticas, el conejo, el ciervo, el zorro y el lince (Córdoba de Oya, 1983; García Atiénzar, 2010; Vega Toscano, 1993). Han sido varios los autores que han encuadrado los niveles inferiores del yacimiento en el Paleolítico superior final, más concretamente en el Magdaleniense (Mateo Saura, 1997-1998; Ripoll López et al., 1997; Serna López, 1999).

\section{c. El Palomar (Yeste)}

El abrigo de El Palomar se localiza en una de las estribaciones de la sierra de Alcaraz (Ripoll López et al., 1997), en el valle del río Tus, un cañón de tipo kárstico que genera la acción hidráulica a su entrada en el actual Pantano de la Fuensanta, $3 \mathrm{~km}$ antes de su desembocadura original en el río Segura (Peña Alonso, 2011 ). Fue descubierto en 1984 por Córdoba de Oya y Vega Toscano (Peña Alonso y Vega Toscano, 2013). El yacimiento es un abrigo de unos $40 \mathrm{~m}$ de largo y tres de profundidad, con una visera de roca caliza. Dependiendo de las condiciones hídricas en las que se encuentre el embalse, podemos encontrar el yacimiento casi totalmente cubierto por el agua, tal y como se encontraba en el año 2012 en el que realizamos nuestra primera visita al mismo, o totalmente descubierto como en 2017, cuando se tomaron las imágenes de este trabajo (Figuras 7 y 8 ). Además, debemos indicar que este es el yacimiento con un estudio lítico más completo y actualizado de todos los que presentamos aquí, sobre todo en lo referente a los niveles gravetienses, tratados por Peña Alonso en su tesis doctoral (2011) y en diversas publicaciones $(2009,2013)$. 


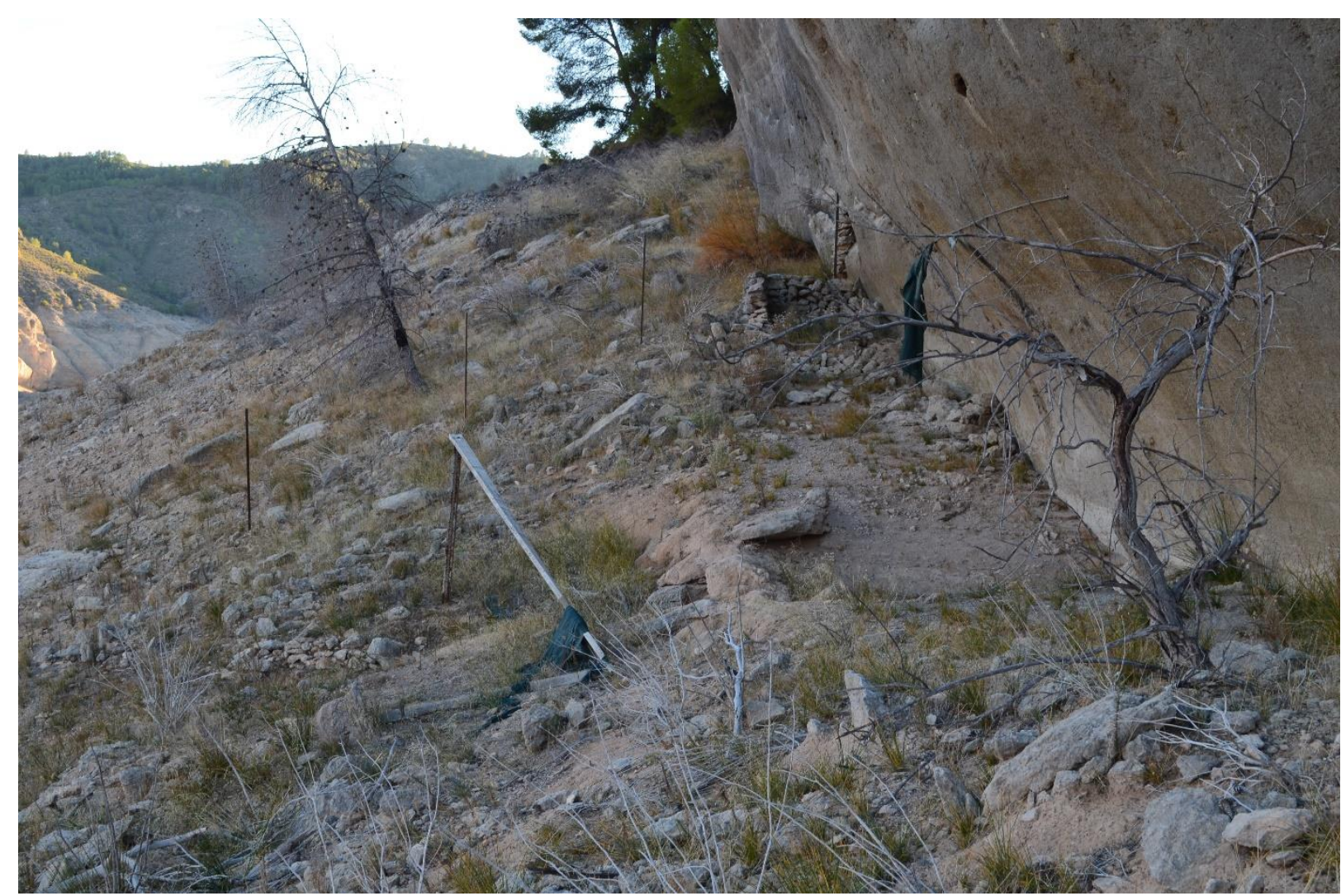

Figura 7. Estado actual del yacimiento de El Palomar. Vista lateral del sondeo realizado junto a la pared del abrigo. Fuente: elaboración propia.

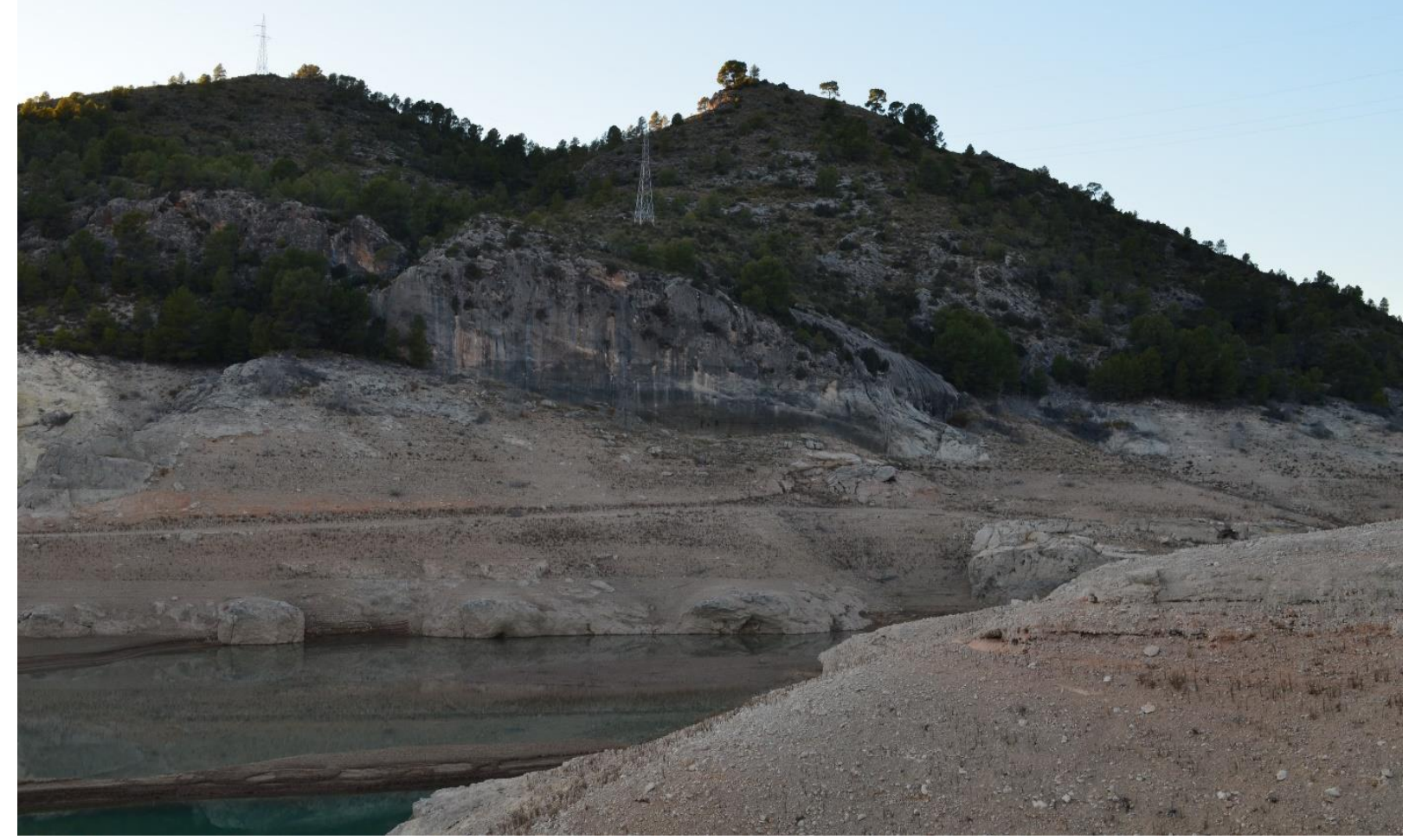

Figura 8. Vista del yacimiento El Palomar desde la margen izquierda del pantano de La Fuensanta. Fuente: elaboración propia. 
Tras una serie de prospecciones en la zona, en 1996 se llevó a cabo la primera campaña de excavación (Vega Toscano y Martín Blanco, 2006). Los trabajos se paralizaron hasta 2004, año en el que continuaron las excavaciones hasta 2008, dirigidas por Vega Toscano, Colino Polo y Peña Alonso (Peña Alonso y Vega Toscano, 2013). En las prospecciones iniciales se hallaron en superficie materiales que podrían ser adscritos al Solutrense superior, tales como puntas foliáceas (Ripoll López et al., 1997), una punta de aletas y pedúnculo, una hojita con retoque plano y cubriente, raspadores de retoque plano y hojitas de dorso, semejantes a los del yacimiento de Molino del Vadico (Córdoba de Oya y Vega Toscano, 1988; Serna López, 1999). Los niveles arqueológicos diferenciados en el área de excavación que colindaba con la pared del abrigo fueron 13, clasificados de la siguiente forma: los niveles XIII-VI pertenecen al Paleolítico medio, los niveles V-III al Paleolítico superior inicial y los niveles II y I al Paleolítico superior final y Holoceno, según Peña Alonso y Vega Toscano (2013).

En los niveles adscritos al Paleolítico medio (XIII-VI) la industria lítica es homogénea, con un mayoritario uso de la cuarcita y con unos sistemas tecnológicos orientados a la extracción de lascas. El más utilizado es el discoide, característico del Musteriense, y también aparecen núcleos de extracción bipolar. Es una industria muy similar a la encontrada en la superficie y en la cata de la zona aluvial del sedimento del yacimiento. De este modo, pese a las dudas que plantea la datación del nivel Vl, que presenta una fecha de $28050 \pm 230$ BP perteneciente al Paleolítico superior inicial, se ha clasificado todo el paquete en el mismo periodo, pudiendo tener en este nivel una de las pruebas de la pervivencia de los grupos neandertales en el sur de la península ibérica (Peña Alonso, 2011 ; Vega Toscano y Martín Blanco, 2006), lo cual se encuadraría dentro de la corriente teórica que defiende la subsistencia de los neandertales hasta momentos muy tardíos y su posible coincidencia en el tiempo con los primeros grupos de Humanos Anatómicamente Modernos (Zilhão y d'Errico, 1999; Zilhão y Pettitt, 2006).

Los niveles pertenecientes al Paleolítico superior inicial han sido los que han centrado la mayoría de estudios hechos por Peña Alonso. La datación del nivel IV, realizada mediante Radiocarbono AMS, ofreció una fecha de $26430 \pm 210$ BP (29470 - 28110 cal BP) (Peña Alonso y Vega Toscano, 2013; Vega Toscano y Martín Blanco, 2006). En general, las dataciones de los niveles $V$ y VI se encuentran entre 31000 y 30000 cal BP y la del nivel III entre 26000 y 25000 cal BP (Peña Alonso, 2013). Estas fechas se sitúan dentro del Paleolítico superior inicial y, presumiblemente, del Gravetiense. La tecnología lítica de estos tres niveles es bastante homogénea, utilizando como materias primas la cuarcita, la caliza y el sílex de forma mayoritaria. La talla está dirigida a la extracción de soportes laminares, en su mayoría con núcleos prismáticos, aunque también tienen presencia los discoides o multifaciales para la obtención de lascas. Los útiles predominantes son: laminitas de retoque marginal, hojitas de dorso y piezas astilladas, estudiadas mediante experimentación arqueológica, y también raspadores y buriles, en un número inferior (Peña Alonso y Vega Toscano, 2013) (Figuras 9 y 10). En cuanto a la adscripción cultural, la presencia mayoritaria del retoque abrupto, junto con técnicas características de otros contextos del Gravetiense mediterráneo hacen que se decante hacia este periodo (Peña Alonso, 2013). 


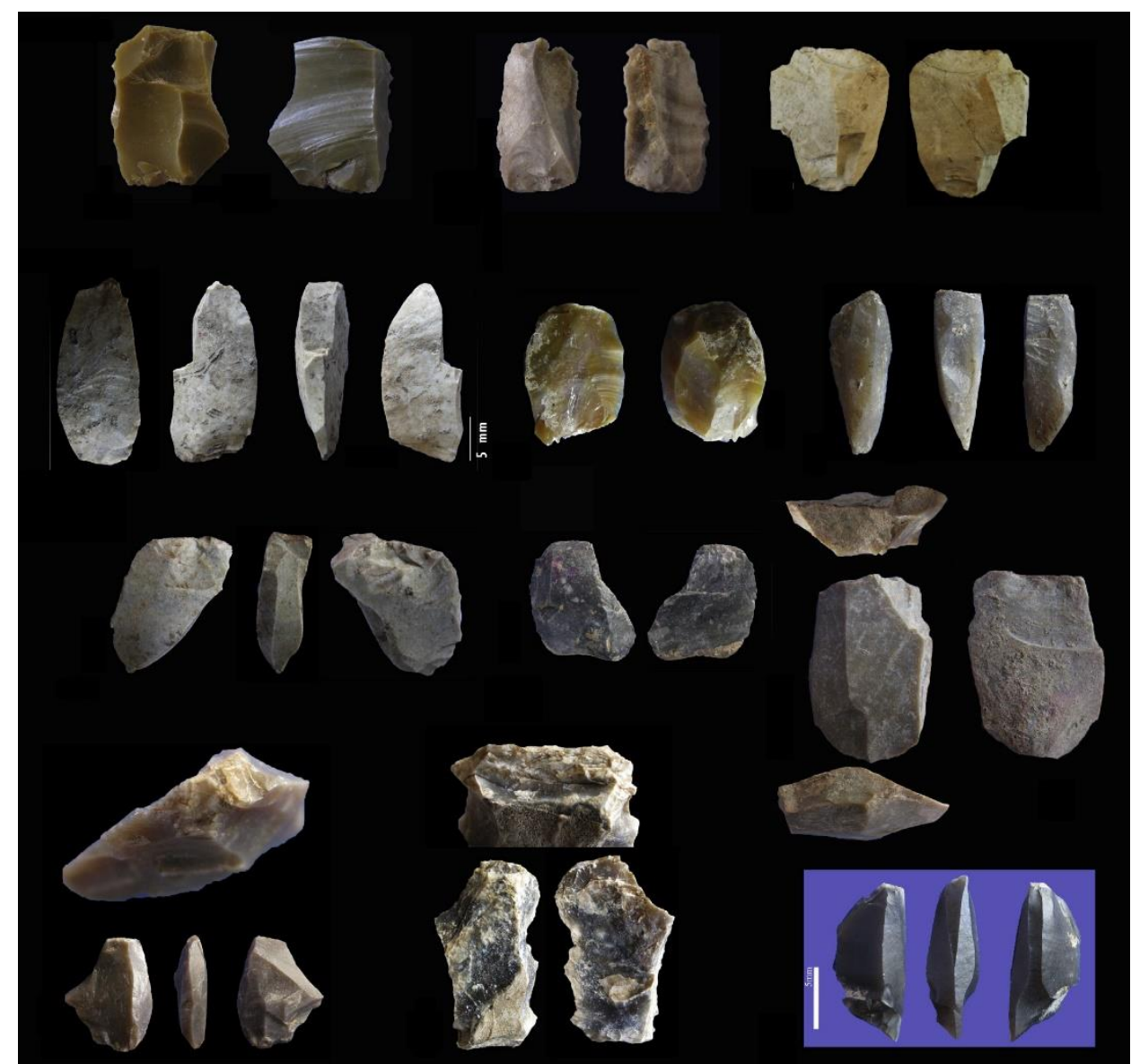

Figura 9. Industria lítica del Abrigo del Palomar. Niveles III-IV-V. Soportes. Fuente: a partir de Peña Alonso, 2013, p. 10.

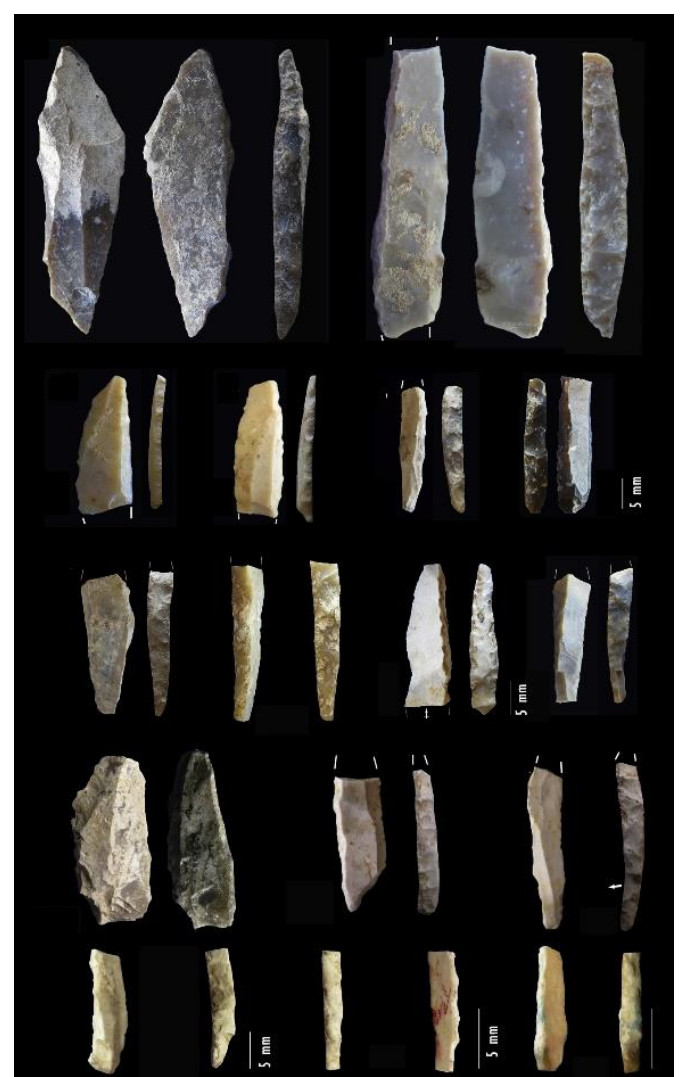

Figura 10. Industria lítica del Abrigo del Palomar. Niveles III-IV-V. Laminitas de dorso. Fuente: a partir de Peña Alonso, 2013, p. 12. 
Finalmente, los niveles II y I se han atribuido de forma generalizada al Paleolítico superior final por los investigadores del yacimiento, aunque se han planteado otras hipótesis. Algunos autores relacionan el nivel III con el Solutrense, debido a la aparición de elementos de aletas y pedúnculo, realizados con retoque profundo, y raspadores de retoque plano (Fernández Gómez y Velasco Ortiz, 2012). Otros autores plantean la posible adscripción del nivel I al Magdaleniense final (García Moreno, 2014).

En definitiva, nos encontramos ante un lugar que ha visto pasar diferentes grupos del Paleolítico medio y superior, que han utilizado este abrigo como lugar de ocupación puntual en el Paleolítico medio, y más estable, a juzgar por la cantidad de restos encontrados y la potencia sedimentaria, en el Paleolítico superior, sobre todo durante el Gravetiense. Este paraje ofrecería una gran cantidad de recursos a sus habitantes, tanto faunísticos y vegetales como líticos e hídricos, que harían del lugar un enclave típico de las ocupaciones paleolíticas.

\section{d. Abrigos de Tus (Yeste)}

Yacimiento situado en un conjunto de abrigos que se abren hacia el río Tus, afluente del Segura, del cual no hemos podido concretar su localización. El relleno de uno de los abrigos fue seccionado durante la realización de una pista forestal y presenta restos de un sedimento de carácter orgánico en el que se localizaron algunos raspadores, hojitas de dorso de sílex y unos pocos restos de fauna. El estudio de estos materiales llevó a paralelizar el yacimiento con los niveles del Paleolítico superior final-Epipaleolítico del yacimiento del Molino del Vadico (Ripoll López et al., 1997; Serna López, 1999).

e. Cueva del Niño (Ayna)

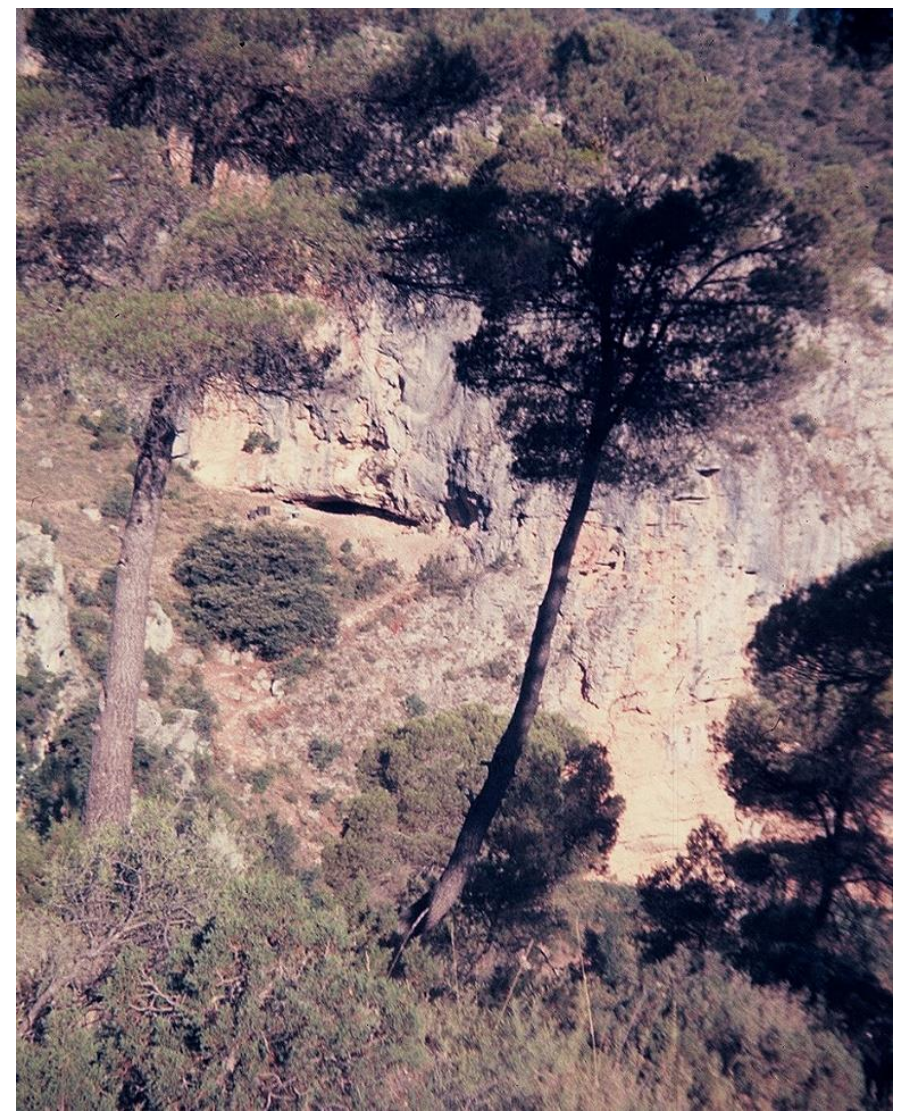

Figura 11. Vista de la Cueva del Niño. Fuente: I. Davidson, 1973 (García Moreno et al., 2014, p. 223). 
En 1970 un grupo de excursionistas descubrió el yacimiento de la Cueva del Niño, en el término municipal de Ayna. Se sitúa en las estribaciones del este de la sierra de Alcaraz, en la margen izquierda del Barranco del Infierno, que desemboca en el río Mundo. Alrededor del sitio encontramos pendientes muy escarpadas que dificultan el acceso al mismo. La cavidad, de unos $30 \mathrm{~m}$ de profundidad, se compone por dos grandes salas, separadas por un conjunto de estalactitas, junto a las que se abren otras más pequeñas (García Atiénzar, 2010; García Moreno et al., 2016) (Figura 11).

El primer estudio lo realizó Almagro-Gorbea, sobre las pinturas rupestres paleolíticas y levantinas del yacimiento (Almagro-Gorbea, 1971). Para el conocimiento de las mismas nos remitimos a los análisis realizados por Alonso Tejada y Grimal (1995-1996) y Gárate Maidagán y García Moreno (2011) (Figuras 12 y 13). En cuanto a la cronología se han barajado varias hipótesis, pero tras obtener en 2010 la datación radiocarbónica de un hogar situado bajo las pinturas, que dio una fecha de $22780 \pm 60 \mathrm{BP}$, se han adscrito al Gravetiense final o a inicios del Solutrense, en cualquier caso, anteriores al Magdaleniense (Gárate Maidagán y García Moreno, 2011; García Moreno et al., 2016). Algunos autores, como Almagro-Gorbea (1971) o Fortea Pérez (1978), establecieron por comparación con otros yacimientos, como Parpalló o Mallaetes, que pertenecían al Solutrense final-Magdaleniense inicial (Ripoll López et al., 1997).

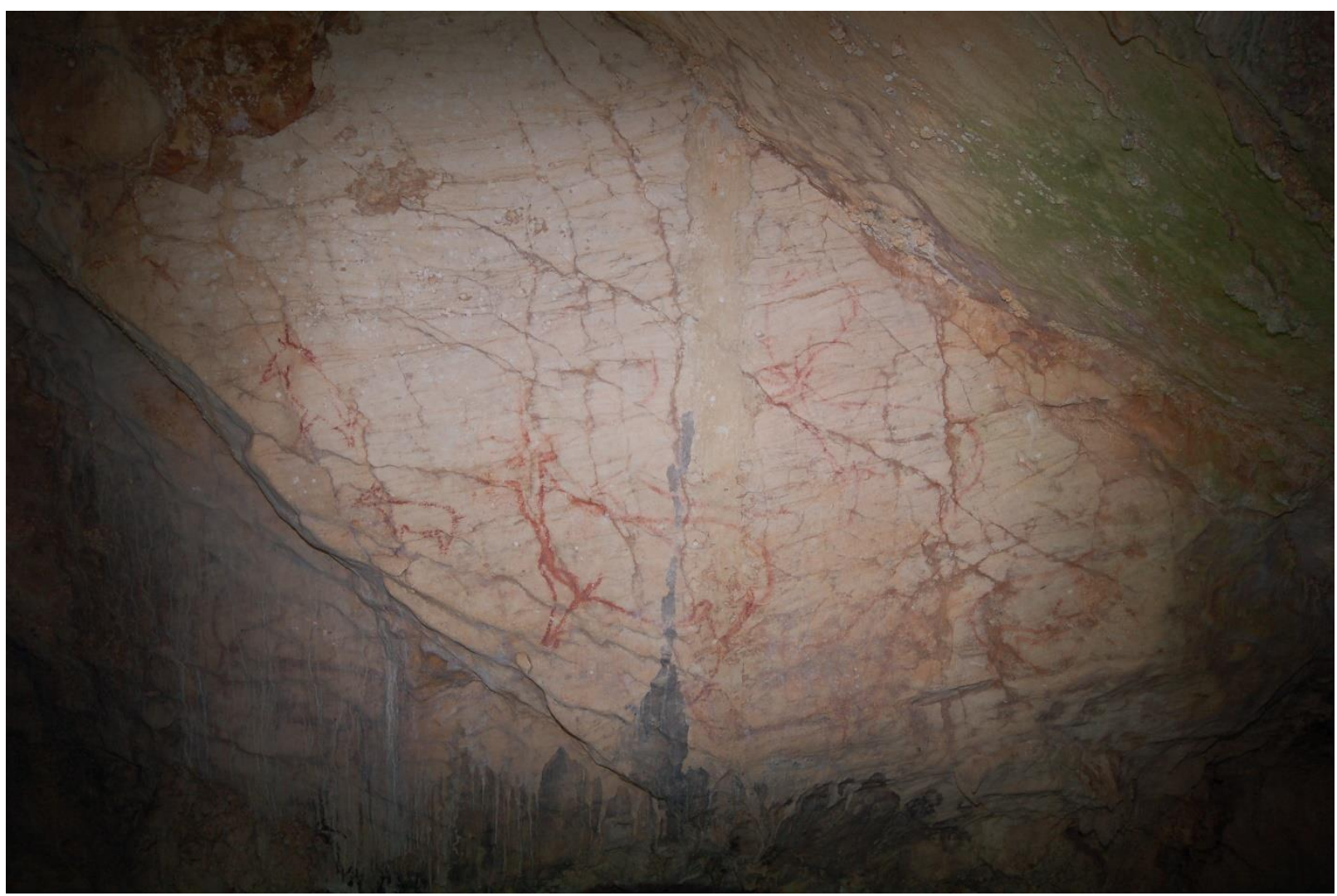

Figura 12. Panel de pinturas rupestres paleolíticas de la Cueva del Niño. Fuente: García Moreno et al., 2016, p. 58. 


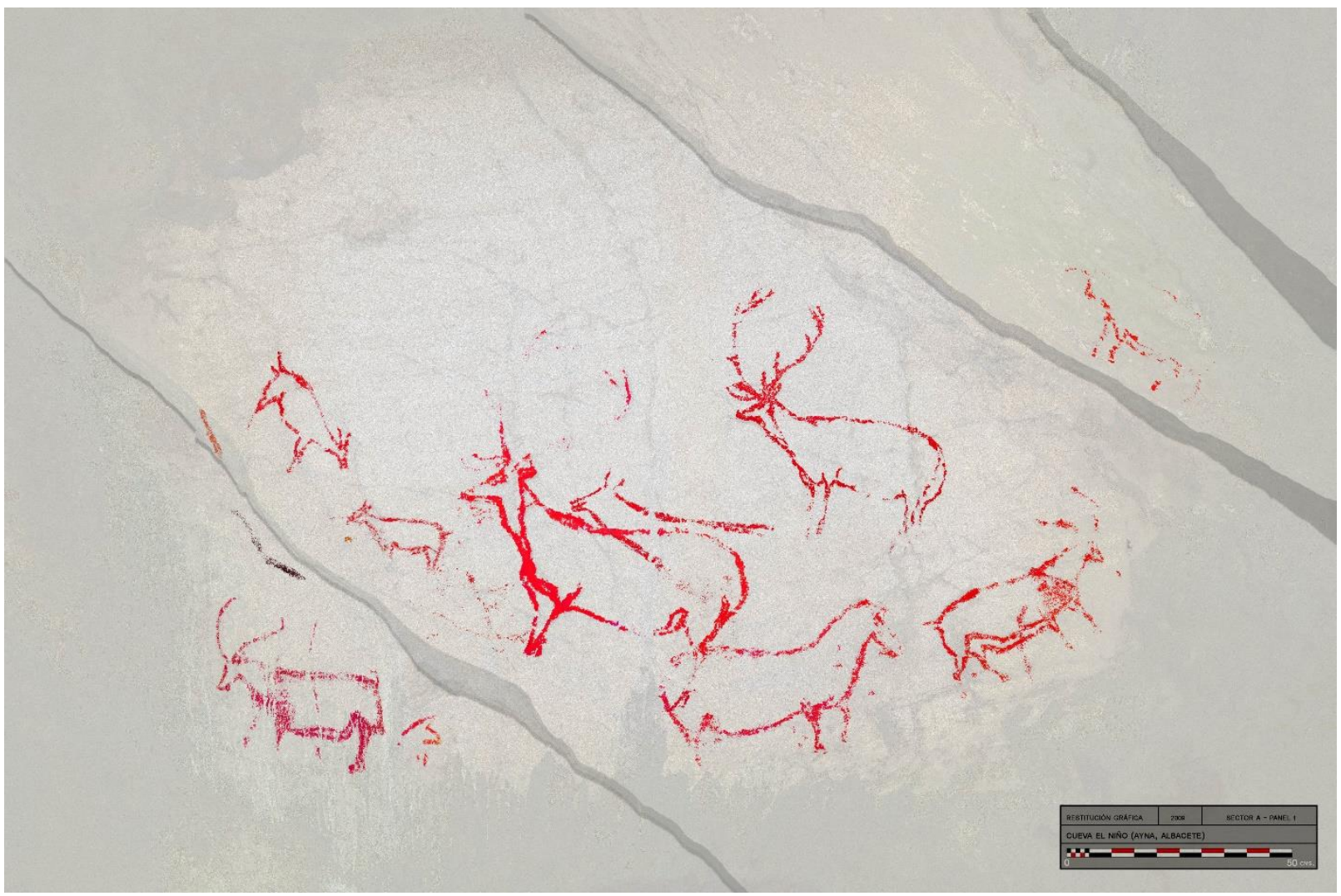

Figura 13. Calco realizado sobre el panel anterior. Fuente: García Moreno et al., 2016, p. 58.

En cuanto a las intervenciones arqueológicas, en primer lugar, se debe indicar que el sedimento del abrigo exterior y del interior de la cavidad ha sufrido varias intrusiones antrópicas, ya sea por parte de expoliadores o por otros motivos (García Moreno, 2011). El equipo de Davidson, auspiciados por el proyecto "Early Agriculture Research Project" de las universidades de Cambridge y Londres, realizó una serie intervenciones en el año 1973 (Davidson y García Moreno, 2013). Sondearon la primera sala de la cueva, bajo el panel principal de pinturas paleolíticas, y el abrigo exterior, junto a la entrada y bajo las pinturas rupestres levantinas. Se constataron en todas ellas niveles paleolíticos, y bajo el panel de arte levantino también se localizaron niveles pertenecientes al Neolítico inicial, datado en $6065 \pm 40$ BP (García Moreno et al., 2016) y al Bronce inicial.

Se contabilizaron 11 niveles estratigráficos, atribuidos inicialmente al Paleolítico medio, Paleolítico superior y Epipaleolítico o Neolítico/Calcolítico. Los niveles que van del XI al III se adscriben al Paleolítico medio. En este conjunto se localizaron 137 restos líticos, la mayoría concentrados en los niveles IV y XI, y siendo la materia prima predominante la cuarcita local, frente al sílex, que se introduce en útiles ya tallados, por lo que debe provenir de afloramientos lejanos, como los del Campo de Hellín, a más de $30 \mathrm{~km}$. El nivel superior de esta secuencia, denominado III-IV, datado entre 33470 y 31975 cal BP (García Moreno et al., 2014), contenía 74 restos líticos, destacando los soportes en forma de lasca y la carencia de núcleos y restos de talla. Las técnicas de talla se corresponden con la de tipo Quina y la Discoide cordal (García Moreno et al., 2014). Según Serna López $(1990,1999)$ es común encontrar este tipo de núcleos en superficie en las inmediaciones de la cueva. Para la talla del sílex el método más usado es el Levallois. Los investigadores sugieren para este nivel una ocupación que pertenecería a un Paleolítico medio final, por la datación obtenida y por los rasgos tecnológicos comunes a otros 
yacimientos del Musteriense mediterráneo en los que también perviven los grupos neandertales (García Moreno et al., 2014).

Los niveles VII, VIII y X presentan restos de ocupaciones efímeras, pues solamente se hallaron 24 piezas líticas, algunas del tipo Levallois y un núcleo discoide. Finalmente, el nivel $\mathrm{XI}$, datado en 55550 BP (García Moreno et al., 2014), presenta 40 restos, de entre los que destaca la presencia de un núcleo de sílex preparado para la obtención de microlascas (García Moreno et al., 2014) (Figuras 14 y 15).
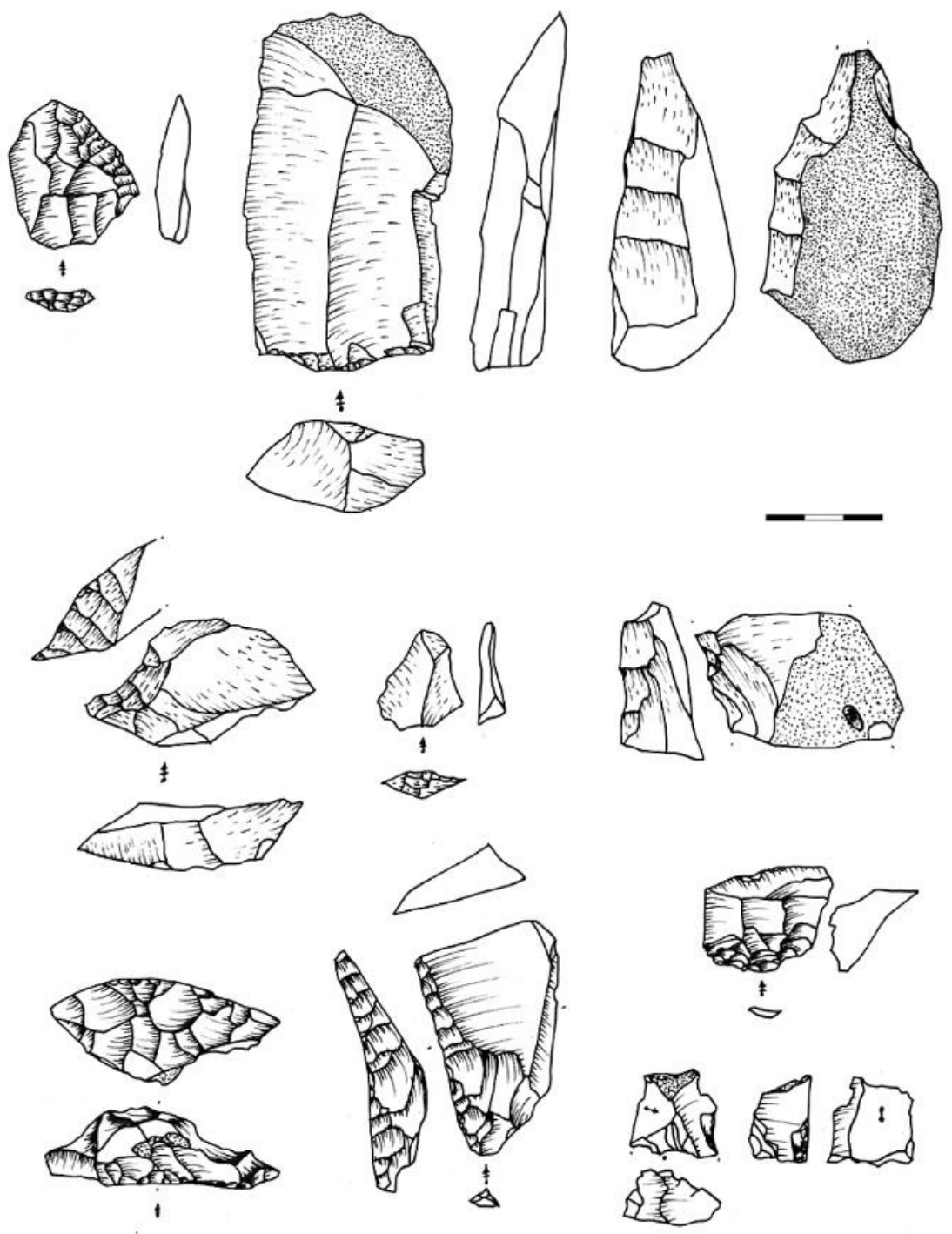

Figura 14. Dibujos de materiales líticos de la Cueva del Niño, pertenecientes a los niveles VII, VIII y XI. Fuente: García Moreno et al., 2014, p. 228. 

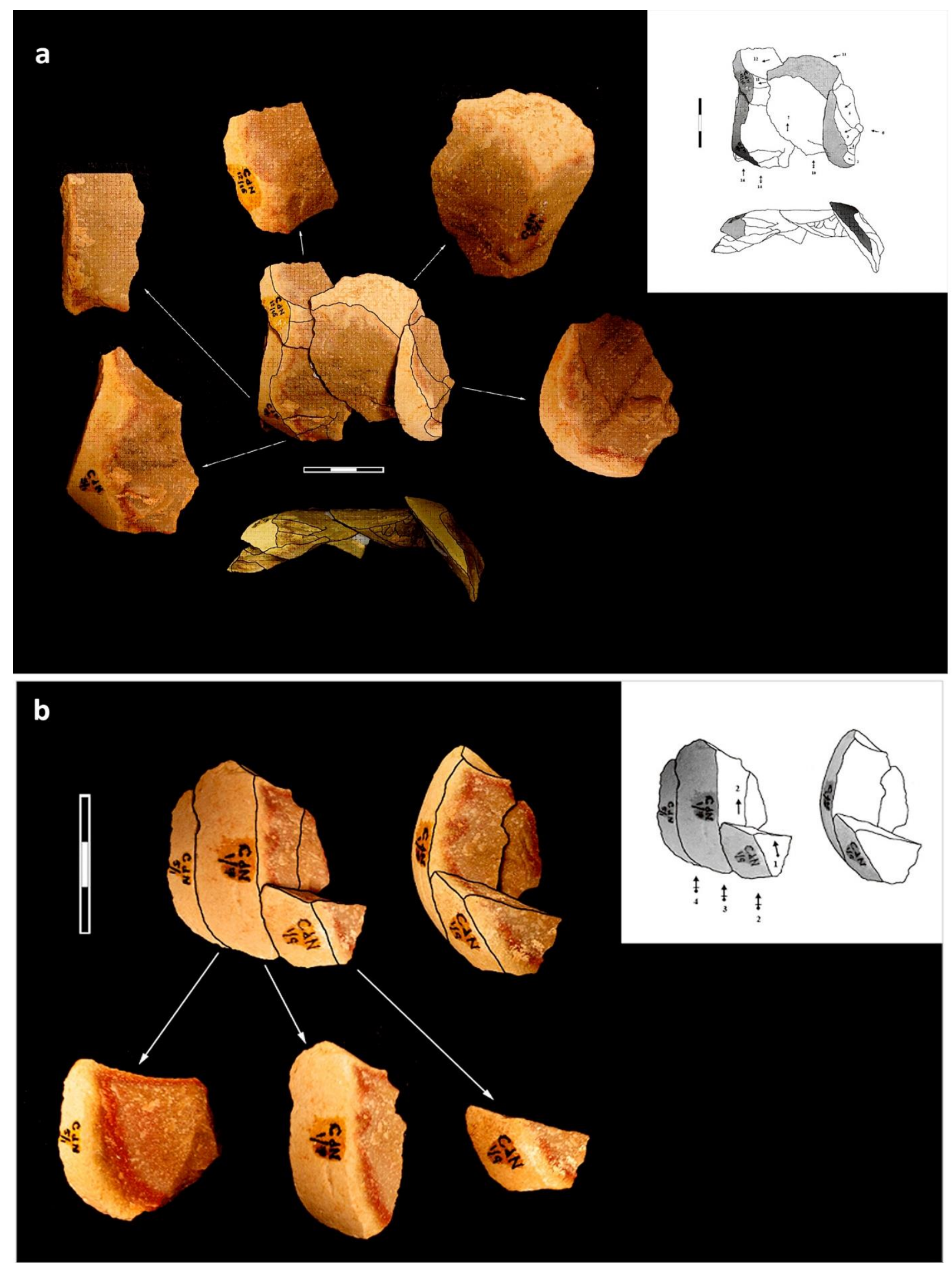

Figura 15. Remontajes de núcleos realizados en cuarcita. Fuente: García Moreno et al., 2014, p. 226.

Superpuestos a este horizonte musteriense, tenemos los niveles II y I, que podrían adscribirse al Paleolítico superior final o al Epipaleolítico por la presencia de industrias microlíticas y laminares, - al Neolítico, por la presencia de cerámica (García Moreno et al., 2016), aunque sin que esto último eliminase la hipótesis anterior. El Paleolítico superior se documenta, aparte de los paneles 
de arte del interior de la cueva, en el sondeo realizado en la primera sala. Como ya hemos indicado, se dató en $22.780 \pm 60$ BP, lo que indicaría momentos finales del Gravetiense o, incluso, inicios del Solutrense (García Moreno et al., 2016) (Figura 16).

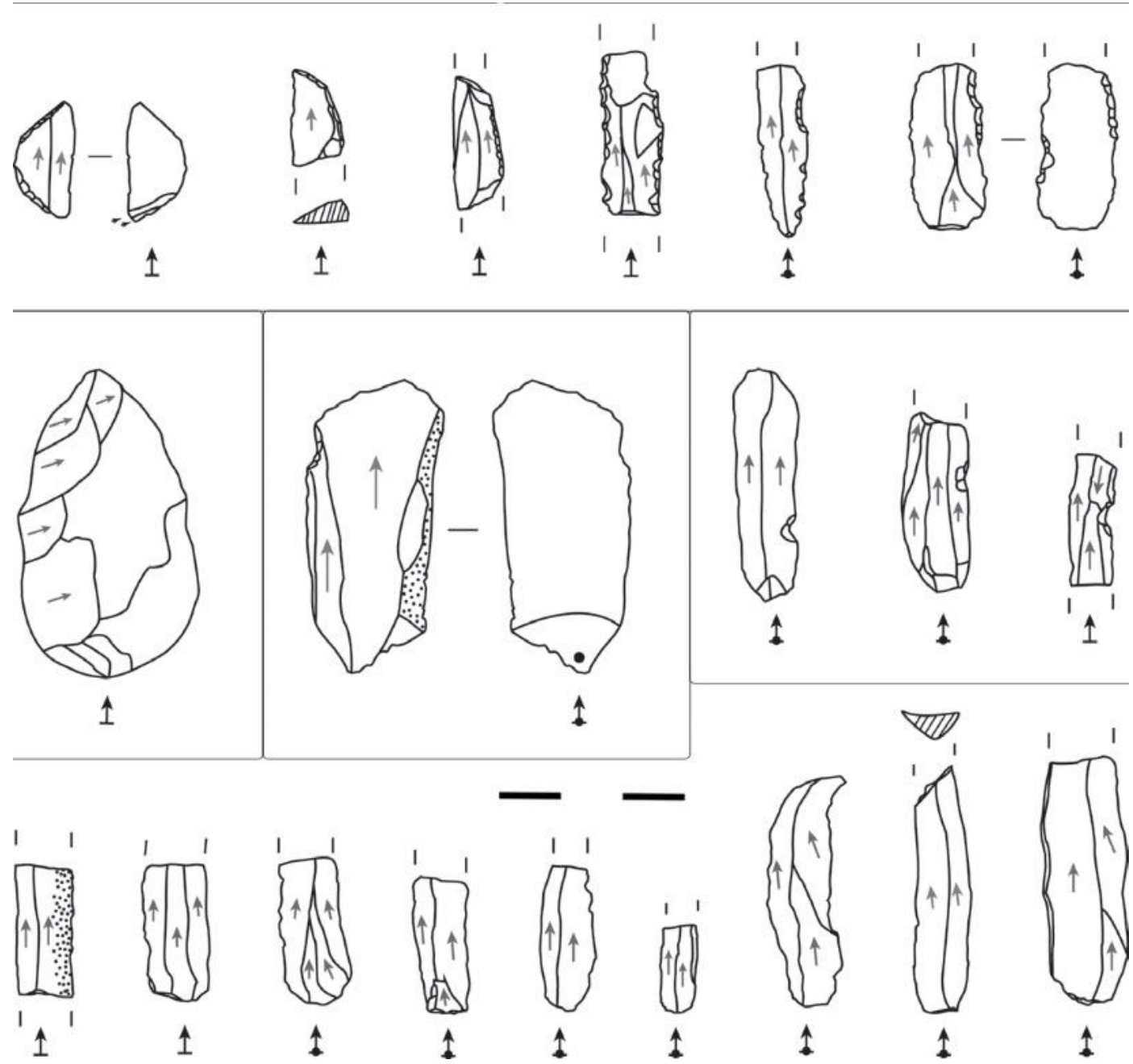

Figura 16. Industria lítica de los niveles superiores de la Cueva del Niño. Fuente: García Moreno et al., 2015, p. 99.

Este yacimiento se trataría de un receptor de visitas puntuales, sobre todo en lo que respecta al Paleolítico medio. La captación de recursos ha ido variando a lo largo de la ocupación del sitio, abarcando grandes áreas en los momentos iniciales y finales de la ocupación, y restringiéndose a lo local en las ocupaciones intermedias. Aun así, la Cueva del Niño sigue siendo un yacimiento de referencia, sobre todo en cuanto al Paleolítico superior, ya que, pese a carecer de una estratigrafía clara para este periodo, contiene las únicas pinturas rupestres paleolíticas de la provincia.

\section{Reflexiones finales}

Como hemos podido observar, gracias a los diversos estudios realizados sobre la habitabilidad de la Meseta, se está comenzando a aceptar dentro del ámbito científico y académico que la presencia de grupos humanos durante el Paleolítico no es algo excepcional (Aubry, 2001; Cacho Quesada et al., 2010; Martín-Lerma, 2015; Zilhão, 1992). Con la realización de la revisión de todos los yacimientos situados en el sur de Albacete, parte de la Submeseta sur, hemos querido 
ayudar a completar este paradigma de la investigación y confirmar que los grupos del Paleolítico tuvieron una presencia constatada en esta zona de la Submeseta sur, habiendo yacimientos de todos los periodos, desde el Paleolítico inferior hasta el Paleolítico superior. Pese a esto, contamos con una escasez destacable de yacimientos atribuibles al Paleolítico inferior y al Paleolítico superior.

El Musteriense es el tecnocomplejo protagonista en nuestra área de análisis, pues a este periodo pertenece la mayoría de conjuntos localizados. Pero debemos tener en cuenta que muchos de estos yacimientos son hallazgos superficiales o estaciones al aire libre, y en su mayoría se encuentran en posición secundaria, incluso cuando se hallan insertos en una estratigrafía geológica conservada, como es el caso de El Pedernaloso. El estudio de yacimientos en posición secundaria es muy limitado y en nuestro caso, al menos todos aquellos que en su toponimia incluyen el nombre de "Rambla de" carecen de un contexto real asociado. Este hecho nos impide conocer el ambiente en el que fueron manufacturadas y utilizadas las herramientas líticas, así como la información económica que nos podrían ofrecer en otras circunstancias, y nos limita solamente a la realización de análisis tipo-tecnológicos. Otro aspecto a tener en cuenta es el sesgo o filtro que cada prospector tiene a la hora de recoger estos materiales superficiales. Pese a la sistematicidad de las prospecciones, somos conscientes de que los objetos de mayor tamaño y vistosidad son recogidos más fácilmente que los restos de talla, fragmentos y otros elementos, por lo tanto, las proporciones estadísticas y funcionales carecen de fiabilidad en estos casos.

Algunos sitios suman a esta característica el hecho de que presentan conjuntos de muy pocas piezas, por lo que se han clasificado de forma muy superficial atendiendo a la materia prima y a la tecnología predominante. Pero esta clasificación podría variar en caso de localizarse más piezas, por lo que las tratamos como provisionales y no basaremos nuestras reflexiones en ellas de modo definitivo. Las prospecciones realizadas en el área del Campo de Hellín y en la cuenca del río Mundo han estado más orientadas hacia estos hallazgos, que presentan unas características diferentes que las de los yacimientos pertenecientes al Paleolítico superior. Este hecho, junto a la falta de prospecciones sistemáticas en la zona de la cuenca del río Segura, en la que se reúnen todos los yacimientos de cronologías pertenecientes al Paleolítico superior, podría ser uno de los motivos de la escasez de hallazgos pertenecientes a este último periodo.

Pese a estas problemáticas, sí que contamos con ciertos datos que nos ayudan a entender el contexto en el que se movieron los grupos del Paleolítico inferior y medio en nuestra zona de análisis. Yacimientos como la Fuente de Hellín, el Polope, el Pedernaloso o la Cueva del Niño, con más cantidad de restos líticos asociados y una recogida más sistemática de los restos, incluso aplicando la metodología de excavación arqueológica en el tercero de ellos, nos permite realizar ciertas reflexiones. En las zonas del Campo de Hellín y del río Segura a su paso por el municipio de Ayna contamos con áreas de captación de recursos utilizadas desde el Paleolítico medio. Muchos de los elementos de sílex que aparecen en la zona están realizados con materias primas procedentes de la Rambla de El Pedernaloso.

También podemos referenciar tres zonas con un posible hábitat estacional o puntual pero recurrente durante el Paleolítico medio, que serían la zona de la Cueva del Niño, en torno al cauce del río Segura, y las áreas lacustres de la Fuente de Hellín y Polope. Estas zonas contienen fuentes estables de agua, recursos vegetales y buena visibilidad para la caza de aquellas especies asociadas al entorno lacustre, tal y como indican López Campuzano y Jordán Montés 
(1995) en el segundo de los casos. Los grupos que han habitado estas zonas son homogéneos tecnológicamente hablando. Esta conclusión se deriva de la presencia mayoritaria de las técnicas de extracción de lascas predeterminadas con el método Levallois y a través de núcleos discoides.

En cuanto a adscripción cronológica, a falta de una revisión más profunda de los materiales y de nuevos hallazgos que abran el camino hacia otras interpretaciones, podemos decir que los altos índices de presencia de talla Levallois nos sitúan en la mayoría de los espacios en los intervalos OIS 4 y 3 , en momentos más evolucionados del Paleolítico medio. Aquellos espacios donde los hallazgos de bifaces o protobifaces y de altos porcentajes de cantos trabajados, como el área Río Mundo A, habrían sido también escenario de la presencia de estos grupos momentos previos, en el OIS 5, donde el sustrato del Paleolítico inferior todavía está presente. Finalmente, hemos de resaltar que la Submeseta sur pudo ser un lugar de pervivencia de los neandertales. Las fechas más recientes en las dataciones de Paleolítico medio realizadas en El Palomar y en la Cueva del Niño indican que en momentos posteriores al 40.000 BP aun vivían grupos neandertales, al igual que en otras zonas del sur de la península ibérica (Finlayson et al., 2006). Hay que tomar estas dataciones con precaución. Los niveles de los que proceden presentan una industria lítica adscrita al tecnocomplejo Musteriense, pero debemos ser precavidos y enmarcar estos resultados en análisis más amplios con más datos y variantes.

En cuanto al Paleolítico superior, queda patente la escasez de yacimientos, pese a la importancia de los mismos. Debemos tener en cuenta que, aunque contamos con restos arqueológicos desde el Gravetiense hasta el Magdaleniense, no podemos afirmar que esta área geográfica estuviese densamente poblada durante todo el periodo. Lo que sí podemos afirmar es que los asentamientos hallados y estudiados tenían una cierta estabilidad, pues se encuentran próximos a fuentes y cauces de agua y zonas con acceso a recursos, tanto alimenticios como líticos. Será necesario proseguir con las investigaciones. Es reseñable que no contemos con elementos materiales que indiquen la presencia de los Humanos Anatómicamente Modernos durante el Último Máximo Glaciar, salvo las pinturas rupestres de la Cueva del Niño. Que los tres asentamientos con más entidad dentro del periodo, El Palomar, Molino del Vadico y la Cueva del Niño, se correspondan con periodos de clima menos extremo o incluso de mejora climática, es un dato a tener en cuenta a la hora de establecer las posibles relaciones entre la costa y el interior en este periodo.

Tal y como Alcaraz-Castaño refiere en sus publicaciones (2016; Alcaraz-Castaño et al., 2017), según el "modelo de área de paso" estas ocupaciones situadas al interior serían simplemente reflejo del tránsito de las poblaciones del Paleolítico superior, y la población no se asentaría en estas zonas hasta la mejora climática del Tardiglaciar, con la llegada del Magdaleniense. Esta teoría está sustentada en escasos datos y con las recientes investigaciones puede llegar a ser desmentida $\circ$ al menos matizada. Pero, íqué conclusiones podemos extraer en referencia a las relaciones de estos grupos que dejaron sus restos en el interior de la Submeseta sur y los que habitaban en la costa levantina? Podríamos estar ante poblaciones independientes, con tradiciones técnicas, en cuanto a la industria lítica y el arte, diferenciadas, pero todavía carecemos de datos suficientes para afirmar esta posibilidad, aunque debemos ser conscientes de que generalmente los grupos paleolíticos desarrollaban sus actividades en áreas definidas, no en zonas situadas a cientos de kilómetros, como norma general (Alcaraz-Castaño, 2016). Este hecho, junto con la importancia estratigráfica de los escasos yacimientos con los que contamos, indica que estos lugares fueron ocupados con asiduidad. Como segunda hipótesis, se plantean 
estos yacimientos como estaciones de paso en las que se buscaba la captación de uno o varios recursos, como por ejemplo en el yacimiento de la Cueva del Parco (Lleida), situado también al interior $y$ en el que estudios paleoeconómicos muestran una especialización en la caza estacional de la cabra durante el Magdaleniense, al igual que ocurre en la Cueva del Niño en estadios anteriores. Estas incursiones o penetraciones hacia el interior se realizarían a través de los cursos fluviales (Fullola Pericot et al., 2005), destacando en el caso del sur de Albacete que todos los yacimientos adscritos al Paleolítico superior con una potencia importante están situados junto a los ríos Mundo y Segura. Por lo tanto, contamos con dos reflexiones acerca de las relaciones Levante-interior que solo podremos resolver con la aparición de nuevos datos (Figura 17).

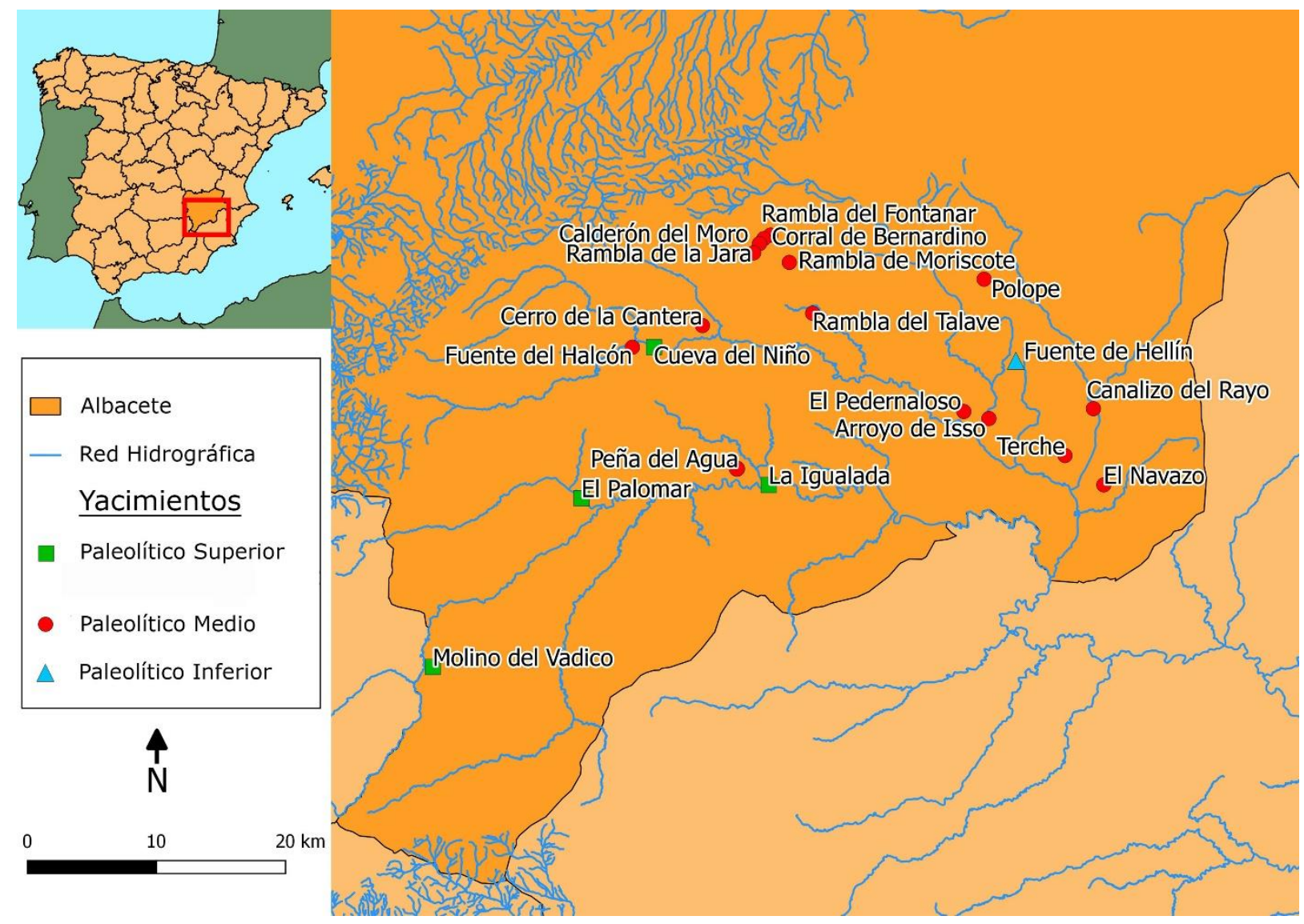

Figura 17. Mapa de localización geográfica de los yacimientos citados con respecto a la red hidrográfica del río Segura. Yacimientos sin localizar: Cueva de los Morciguillos y Abrigos de Tus. Fuente: elaborado por Víctor Martínez García y Noelia Sánchez-Martínez.

Como ya resaltamos en la introducción del estudio, muchos autores a lo largo de la historia de la investigación llegaron a la conclusión de que la Meseta estuvo generalmente desocupada durante el Paleolítico. Este paradigma ha sido utilizado por docentes en las aulas universitarias a la hora de explicar los procesos de expansión de los grupos paleolíticos por la península ibérica. Creemos que los estudios realizados en el área de la Submeseta sur $y$, más concretamente, en el sur de Albacete, pueden servir para explicar de forma didáctica dos aspectos. El primero de ellos sería la evolución propia de la historia de la investigación sobre un aspecto concreto, cómo se da y cómo evoluciona el pensamiento y el conocimiento científico; y el segundo sería la propiamente dicha evolución del poblamiento en una zona de interior, la necesidad de analizar los yacimientos de forma correcta, reconociendo sus carencias y sus aportaciones, el medio ambiente, el clima y, 
también, como se han desarrollado las propias investigaciones y si eso influye o no en las interpretaciones.

Finalmente nos gustaría destacar los grandes planteamientos futuros que hay para continuar con estos estudios. Sería necesario realizar una revisión de los materiales hallados en algunos yacimientos, que fueron estudiados hace varias décadas, para aplicar nuevas técnicas por si pudieran ofrecernos más información. La necesidad de plantear una serie de prospecciones exhaustivas en toda el área de estudio, sobre todo en la zona sur, que abarca los municipios de Yeste, Letur y Nerpio, con el objetivo de hallar yacimientos susceptibles de ser excavados, es patente. La gran cantidad de surgimientos y cauces de agua puede ser el punto inicial de estas prospecciones. La realización de catas y sondeos en los yacimientos de nueva localización o en algunos de los ya estudiados podría ser interesante para conseguir nuevos datos y actualizar los que ya tenemos.

\section{Agradecimientos}

Mostramos nuestro agradecimiento a Juan Francisco Jordán Montés por su colaboración y la puesta a nuestra disposición de información sobre el objeto de nuestro estudio, como prospector principal en la zona. También a Ignacio Martín-Lerma, por su guía en la estructuración del estudio y sus consejos.

\section{Bibliografía}

Alcaraz-Castaño, M. (2016). El Paleolítico superior pre-magdaleniense en el centro de la península ibérica: hacia un nuevo modelo. Arqueología y Prehistoria del Interior Peninsular, 04 (Extra), 34-48.

Alcaraz-Castaño, M., López-Recio, M., Tapias, F., Cuartero, F., Baena Preysler, J., Ruiz-Zapata, B., Morín, J., Pérez-González, y A., Santonja, M. (2017). The human settlement of Central Iberia during MIS 2: New technological, chronological and environmental data from the Solutrean workshop of Las Delicias (Manzanares River Valley, Spain). Quaternary International, 431, 104-124.

Almagro-Gorbea, M. (1971). La cueva del Niño (Albacete) y la cueva de La Griega (Segovia): dos yacimientos de arte rupestre recientemente descubiertos en la Península lbérica. Trabajos de Prehistoria, 28(1), 9-68.

Alonso Tejada, A. (1999). Cultura artística y cultura material: ¿̇Un escollo insalvable? Bolskan, 16, 71-107.

Alonso Tejada, A. y Grimal, A. (1995-1996). Santuarios parietales compartidos en la Prehistoria: la Comunidad de Murcia como paradigma. Anales de Prehistoria y Arqueología de la Universidad de Murcia, $11-12$, 39-58.

Aubry, T. (2001). L'occupation de la basse vallée du Côa pendant le Paléolithique supérieur. En J. Zilhão, T. Aubry y A. F. Carvalho (eds.), Les premiers hommes modernes de la Péninsule Ibérique. Actes du Colloque de la Commission VIII de I'UISPP. Trabalhos de Arqueologia, 17 (pp. 253-273). Lisboa: Instituto Português de Arqueologia.

Brevil, H. (1928). Station moustérienne et peintures préhistoriques du 'Canalizo el Rayo', Minateda (Albacete). Archivo de Prehistoria Levantina, 1, 15-22. 
Cacho Quesada, C., Martos Romero, J. A., Jordá Pardo, J., Yravedra Sainz de los Terreros, J., Avezuela Aristu, B., Valdivia, J. y Martín-Lerma, I. (2010). El Paleolítico superior en el interior de la Península Ibérica. Revisión crítica y perspectivas de futuro. En X. Mangado (ed.), EI Paleolítico superior peninsular. Novedades del siglo XXI (Barcelona 27-29 enero 2010) (pp. 115-136). Barcelona: Seminari d'Estudis i Recerques Prehistòriques. Universitat de Barcelona.

Corchón Rodríguez, M. S. (2002). El Tardiglaciar y la transición al Postglaciar en la Meseta Norte española: una visión de síntesis (reflexiones acerca de las investigaciones realizadas en los últimos 10 años en el territorio de Castilla-León). Zephyrus, 55, 85-142.

Córdoba de Oya, B. (1983). Los materiales del Abrigo del Molino Vadico. Una aproximación a los problemas del Paleolítico Superior Mediterráneo Occidental (Tesis de Licenciatura). Madrid: Universidad Complutense.

Córdoba de Oya, B. y Vega Toscano, L. G. (1988). El Paleolítico de la Sierra del Segura: proyecto de investigación. En I Congreso de Historia de Castilla La Mancha, Vol. II Pueblos y culturas prehistóricas y protohistóricas (pp. 79-85). Toledo: Junta de Comunidades de Castilla-La Mancha.

Cortés Sánchez, M. (2005). El extremo occidente neandertal. El Paleolítico Medio en el Sur de la Península Ibérica. Museo de Altamira. Monografías, 20, 55-74.

Cuadrado Díaz, E. (1947). Yacimientos arqueológicos albacetenses de la cuenca del río Taibilla. Consejería General de Excavaciones. Informes y Memorias, 15, 123-137.

Davidson, I. (1986). The geographical study of Late Palaeolithic stages in Eastern Spain. En G. Bailey y P. Callow (eds.), Stone Age Prehistory. Studies in memory of Charler MacBurney (pp. 95-1 18). Cambridge: Cambridge University Press.

Davidson, I. y García Moreno, A. (2013). La excavación arqueológica de la Cueva del Niño (Ayna, Albacete) de 1973: secuencia estratigráfica y materiales. Al-Basit, 58, 91-117.

Fernández Gómez, A. A. y Velasco Ortiz, A. (2012). El Solutrense en Madrid (España): análisis bibliográfico y comparativo. Espacio, Tiempo y Forma, Serie I, Nueva época, Prehistoria y Arqueología, 5, 119-129.

Finlayson, C., Giles Pacheco, F., Rodríguez-Vidal, J., Fa, D., Gutiérrez López, J. M., Santiago Pérez, A., Finlayson, G., Allue, E., Baena Preysler, J., Cáceres, I., Carrión, J. F., Fernández Calvo Y., Gleed-Owen, C. P., Jiménez Espejo, F. J., López, P., López Sáez, J. A., Riquelme Cantal, J. A., Sánchez Marco, A., Giles Guzmán, F., Brown, K., Fuentes, N., Vilarino, C. A., Villalpando, A., Stringer, C. B., Martínez Ruiz, F. y Sakamoto, T., (2006). Late survival of Neanderthals at the southernmost extreme of Europe. Nature, 443, 850-853.

Fortea Pérez, F. J. (1978). Arte paleolítico del Mediterráneo español. Trabajos de Prehistoria, 35, 99-149.

Fullola Pericot, J. M., Villaverde Bonilla, V., Sanchidrián Torti, J. L., Aura Tortosa, J. E., Fortea Pérez, F. J. y Soler i Masferrer, N. (2005). El Paleolítico Superior Mediterráneo Ibérico. En J. L. Sanchidrián Torti, A. M. Márquez Alcántara y J. M. Fullola Pericot (eds.), La cuenca mediterránea durante el Paleolítico Superior: 38.000-10.000 años. Simposio de la Cueva de Neria (pp. 192-213). Málaga: Fundación Cueva de Neria. 
Gárate Maidagán, D. y García Moreno, A. (2011). Revisión crítica y contextualización espaciotemporal del arte parietal paleolítico de la Cueva de El Niño (Ayna, Albacete). Zephyrus, 63, 15-39.

García Atiénzar, G. (2010). El yacimiento de la Fuente de Isso (Hellín) y el poblamiento neolítico en la provincia de Albacete. Albacete: Instituto de Estudios Albacetenses Don Juan Manuel de la Excma. Diputación de Albacete.

García Moreno, A. (2011). Nuevos datos referentes a la Cueva del Niño (Ayna, Albacete). Aparición de un pozo de origen antrópico. Al-Basit, 56, 259-265.

García Moreno, A. (2014). El poblamiento paleolítico de la cuenca del río Mundo (Albacete). Archivo de Prehistoria Levantina, 30, 1-16.

García Moreno, A., Cubas, M., Davidson, I., Gárate, D., López-Dóriga, I., Marín-Arroyo, A. B., Ortiz, J. E., Polo Díaz, A., Ríos-Garaizar, J., San Emeterio, A. y de Torres, T. (2016). Revisión y estudio multidisciplinar del yacimiento de la Cueva del Niño (Ayna, Albacete). En B. Gamo Parras y R. Sanz Gamo (coords.), Actas de la I Reunión Científica de Arqueología de Albacete (pp. 51-68). Albacete: Instituto de Estudios Albacetenses Don Juan Manuel.

García Moreno, A., Cubas, M., Marín-Arroyo, A. B., Ríos Garaizar, J., Ortiz, J. E., Torres, T. de, López Dóriga, l., Polo Díaz, A., San Emeterio Gómez, A. y Gárate Maidagan, D. (2015). El Neolítico de la Cueva del Niño (Ayna, Albacete) en el contexto de la Sierra del Segura. Complutum, 26(1), 91-111.

García Moreno, A., Ríos Garaizar, J., Marín Arroyo, A. B., Ortiz, J. E., Torres, T. de y LópezDóriga, I. (2014). La secuencia musteriense de la Cueva del Niño (Ayna, Albacete) y el poblamiento neandertal en el sureste de la Península lbérica. Trabajos de Prehistoria, 71 (2), 221-241.

Hernández Pérez, M. S. (2002). El poblamiento prehistórico de Albacete. Estado actual y perspectivas de futuro. En R. Sanz Gamo (coord.), II Congreso de Historia de Albacete. Del 22 al 25 de Noviembre. I Arqueología y Prehistoria (pp. 11-10). Albacete: Instituto de Estudios Albacetenses Don Juan Manuel de la Excma. Diputación de Albacete.

Jiménez Lorente, S., Jordán Montés, J. F. y Ayala Juan, M. M. (1995-1996). El taller de la Ermita del Pedernaloso (Hellín, Albacete). Nuevas aportaciones de los talleres de sílex al aire libre. Anales de Arqueología y Prehistoria de la Universidad de Murcia, 1 1-1 2, 17-22.

Jordán Montés, J. F. (1991-1992). Los conjuntos de insculturas del Valle de Minateda (Hellín, Albacete). Anales de Prehistoria y Arqueología de la Universidad de Murcia, 7-8, 21-33.

Jordán Montés, J. F. (1992). Prospección arqueológica en la comarca de Hellín-Tobarra (metodología, resultados y bibliografía). Al-Basit, 31, 183-227.

Jordán Montés, J. F., García Cano, J. M. y Page del Pozo, V. (2006). Desde Heliké hasta llunum: El poblamiento ibérico en Elche de la Sierra (Albacete). Al-Basit, 50, 5-80.

Jordán Montés, J. F. y López Precioso, F. J. (1993). El entorno arqueológico de La Camareta (Hellín, Albacete). Antigüedad y Cristianismo, 10, 69-84.

López Campuzano, M. (1993-1994). Yacimientos musterienses al aire libre de la Región de Murcia y sur de Albacete: pautas de asentamiento, incidencia de la materia prima y variabilidad de la industria lítica. Anales de Prehistoria y Arqueología de la Universidad de Murcia, 9-10, 5-22. 
López Campuzano, M. y Jordán Montés, J. F. (1995). El yacimiento musteriense de la laguna de El Polope (Tobarra, Albacete). Análisis del conjunto lítico y su valoración económica. AlBasit, 37, 5-35.

López Campuzano, M., Jordán Montés, J. F. y Marín de Espinosa Sánchez, J. A. (2003). El yacimiento paleolítico de la Fuente del Halcón (Ayna, Albacete) y su entorno arqueológico: la Cueva del Niño y otros yacimientos prehistóricos. PLEITA Revista del Museo Municipal "Jerónimo Molina", 6, 19-39.

Martín-Lerma, I. (2015). Funcionalidad de la industria lítica magdaleniense del interior peninsular: la Peña de Estebanvela (Ayllón, Segovia) (Tesis Doctoral). Madrid: Universidad Nacional de Educación a Distancia.

Mateo Saura, M. A. (1997-1998). Arte rupestre y neolitización en el alto Segura. Anales de Prehistoria y Arqueología de la Universidad de Murcia, 13-1 4, 39-45.

Mayor Benadero, A. (2017). La desaparición de los neandertales en la península ibérica. Análisis crítico de la bibliografía. DAMA. Documentos de Arqueología y Patrimonio Histórico, 2, 11 27.

Montes Bernárdez, R., Martínez Andreu, M., y Jordán Montés, J. F. (1984). El yacimiento paleolítico de La Fuente. Hellín (Albacete). En R. Sanz Gamo (coord.), Congreso de Historia de Albacete. Volumen I Arqueología y Prehistoria (pp. 29-39). Albacete: Instituto de Estudios Albacetenses de la Excma. Diputación Provincial.

Montes Bernárdez, R. y Rodríguez Estrella, T. (1985). Estudio arqueológico de un yacimiento achelense ubicado en la Fuente de Hellín y su contexto geológico regional. Al-Basit, 16, 45 78.

Muñoz lbáñez, F. J. (1999). Algunas consideraciones sobre el inicio de la arquería prehistórica. Trabajos de Prehistoria, 56(1), 27-40.

Muñoz lbáñez, F. J., Márquez Mora, B. y Ripoll López, S. (2012). La punta de aletas y pedúnculo del Solutrense extracantábrico, de los "dimonis" al arco. Espacio, tiempo y forma. Serie I, Prehistoria y arqueología, 5, 477-490.

Peña Alonso, P. de la (2009). Revisión crítica de los conjuntos líticos gravetienses y su contexto arqueológico en la Península lbérica. Complutum, 20(1), 29-53.

Peña Alonso, P. de la (2011). Sobre la unidad tecnológica del Gravetiense en la Península lbérica: implicaciones para el conocimiento del Paleolítico superior inicial (Tesis Doctoral). Madrid: Universidad Complutense de Madrid.

Peña Alonso, P. de la (2013). The beginning of the Upper Paleolithic in the Baetic Mountain area (Spain). Quaternary international, 31 8, 69-89.

Peña Alonso, P. de la y Vega Toscano, L. G. (2013). Bipolar knapping in gravettian occupations at El Palomar rockshelter (Yeste, Southeastern Spain). Journal of Anthropological Research, $69,33-64$.

Ripoll López, S., Cacho Quesada, C. y Municio González, L. J. (1997). El Paleolítico superior en la Meseta. Espacio, Tiempo y Forma. Serie I, Prehistoria y Arqueología, 10, 55-87.

Sánchez-Martínez, N. (2019). Evolución del poblamiento en el levante peninsular durante los periodos Auriñaciense y Gravetiense. Desmintiendo la "despoblación" del área murciana. 
Ponencia en II Jornadas de Jóvenes Investigadores en Arqueología de la Región de Murcia. Murcia.

Serna López, J. L. (1990). Hallazgos musterienses en la cuenca media del río Mundo (Albacete). Al-Basit, 26, 5-26.

Serna López, J. L. (1997). Consideraciones sobre economía y ocupación del territorio durante la Prehistoria inicial. El caso de los yacimientos paleolíticos y epipaleolíticos de la cuenca del río Mundo. Archivo de Prehistoria Levantina, 22, 57-71.

Serna López, J. L. (1999). El Paleolítico medio en la provincia de Albacete. Albacete: Instituto de Estudios Albacetenses Don Juan Manuel.

Straus, L. G. (1991). Southwestern Europe at the Last Glacial Maximum. Current Anthropology, 32(2), 189-199.

Straus, L. G. (2018). The Upper Paleolithic of Iberia. Trabajos de Prehistoria, 75(1), 9-51.

Vega Toscano, L. G. (1993). Excavaciones en el Abrigo del Molino del Vadico (Yeste, Albacete). El final del Paleolítico y los inicios del Neolítico en la sierra alta del Segura. En J. Blánquez, R. Sanz y M. T. Musat (coords.), Arqueología en Albacete: Jornadas de Arqueología Albacetenses en la Universidad Autónoma de Madrid (pp. 19-32). Toledo: Junta de Comunidades de Castilla-La Mancha.

Vega Toscano, L. G. y Martín Blanco, P. (2006). Análisis preliminar de las cadenas operativas en el material lítico procedente del nivel IV del Abrigo del Palomar (Yeste, Albacete). En E. Baquedano y J. M. Maíllo (eds.), Miscelánea en homenaje a Victoria Cabrera. Zona Arqueológica, 7(1) (pp. 396-405). Madrid: Museo Arqueológico Regional.

Wood, R. E., Barroso-Ruíz, C., Caparrós, M., Jordá Pardo, J. F., Galván Santos, B., Higham, T. F. G. (2013). Radiocarbon dating of the last Neanderthals. Proceedings of the National Academy of Sciences, 110(8), 2781-2786.

Zilhão, J. (1992). Estratégias de povoamiento e subsistencia no Paleolítico e no Mesolítico de Portugal. En A. Moure (ed.), Elefantes, ciervos y ovicaprinos. Economía y aprovechamiento del medio en la Prehistoria de España y Portugal (pp. 149-162). Santander: Universidad de Cantabria.

Zilhão, J. (2000). The Ebro frontier: a model for the late extinction of lberian Neanderthals. En C. Stringer, R. N. E. Barton y C. Finlayson (eds.), Neanderthals on the edge: 150th Anniversary Conference of the Forbes' Quarry Discovery Gibraltar (pp. 111 -121). Oxford: Oxbow Books.

Zilhão, J. (2006). Chronostratigraphy of the Middle-to-Upper Paleolithic Transition in the Iberian Peninsula. Pyrenae, 37, 7-84.

Zilhão, J. (2009). The Ebro frontier revisited. En Camps, M. y Szmidt, C. (eds.), The Mediterranean from 50,000 to 25,000 BP: Turning Points and New Directions (pp. 293-311). Oxford: Oxbow Books.

Zilhão, J. (2013). Neandertal-Modern human contact in western Eurasia: issues of dating, taxonomy, and cultural associations. En T. Akazawa, Y. Nishiaki y K. Aoki (eds.), Dynamics of Learning in Neandertals and Modern Humans Volume 1 : Cultural Perspectives (pp. 21-57). Tokyo: Springer. 
Zilhão, J., Anesin, D., Aubry, T., Badal, E., Cabanes, D., Kehl, M., Klasen, N., Lucena, A., MartínLerma, I., Martínez, S., Matias, H., Susini, S., Steier, P., Wild, E. M., Angelucci, D. E., Villaverde Bonilla, V. y Zapata, J. (2017). Precise dating of the Middle-to-Upper Paleolithic transition in Murcia (Spain) supports late Neandertal persistence in Iberia. Heliyon, 3(11).

Zilhão, J., Banks, W. y d'Errico, F. (2015). Is the Modern vs. Neandertal dichotomy appropriate any longer for the technocomplexes of the Middle-to-Upper Paleolithic transition? Abstracts, European Society for the Study of Human Evolution, 215.

Zilhão, J., y d'Errico, F. (1999). The chronology and taphonomy of the earliest Aurignacian and its implications for the understanding of Neandertal extinction. Journal of world prehistory, $13(1), 1-68$.

Zilhão, J., y Pettitt, P. (2006). On the new dates for Gorham's Cave and the late survival of Iberian Neanderthals. Before Farming, 2006(3), 95-122. 


\section{Panta Rei}

PANTA REl es una revista digital de investigación orientada a la Historia y la Didáctica de la Historia. Su principal objetivo es la transmisión del conocimiento científico, dando una oportunidad también a los jóvenes investigadores que quieren abrirse camino en el estudio de las ciencias humanas y sociales. Se compone de estudios originales relacionados con la disciplina histórica así como su didáctica y difusión. Las diferentes secciones que componen la revista son: artículos de investigación, entrevistas a profesionales, recensiones de monografías de actualidad y crónicas de congresos o eventos científicos relevantes.

Todos los artículos publicados son objeto de un proceso de revisión a cargo de un mínimo de dos evaluadores, que se consideran expertos en el ámbito temático del artículo propuesto. Nuestro deseo es poder ofrecer unos contenidos rigurosos, de calidad y de interés.

El CEPOAT (Centro de Estudios del Próximo Oriente y la Antigüedad Tardía de la Universidad de Murcia) es la institución encargada de la coordinación y gestión de la revista, desde donde anualmente se lanzará la convocatoria para aquellos que estén interesados en publicar sus trabajos, siempre relacionados con la Historia y la Didáctica de la Historia.

PANTA REI is a digital journal focused on History and Teaching History. Its main objective is the transmission of scientific knowledge by giving also an opportunity to young researchers who want to make their way in the study of human and social sciences. It is composed by original studies related to History, as well as its didactics and promotion. The different sections of this journal are: research articles, interviews to professionals, recensions on monographs about current issues and reports about congresses or relevant scientific events.

All the articles published are subject to a revision process carried out by a minimum of two reviewers who are considered to be experts in the field of the article proposed. Our wish is to offer rigorous contents with quality and being of interest to the reader.

CEPOAT (Centre of Studies of the Middle East and Late Antiquity of the University of Murcia) is the institution in charge of the coordination and management of this journal. This is the centre from where the call for papers will be launched annually for all the people interested in publishing their papers, always related to History and Teaching History. 


\section{Normas de publicación}

El autor se compromete a enviar trabajos originales, que no se encuentren publicados en otras revistas ni en otros idiomas. Así mismo, el mismo artículo no podrá ser presentado en otras revistas mientras dure el proceso de evaluación.

\section{Envío y presentación de originales}

Las normas de edición y forma de envío de artículos a la revista se pueden consultar en https://revistas.um.es/pantarei/

Para la redacción de los trabajos se tendrá en cuenta el Manual de la American Psychological Association, en su $7 .^{a}$ edición. La extensión máxima de los trabajos será de 25 páginas. La revista acepta originales escritos en español o inglés.

\section{Proceso de valoración y evaluación}

Una vez recibidos los trabajos, la Revista realizará una primera valoración. Si el trabajo enviado se ajusta a las normas de presentación propuestas, la temática es coincidente con la línea editorial de la revista y posee la calidad científica necesaria, será remitido al consejo asesor para una primera evaluación. Si no es así en este primer paso se puede rechazar directamente los documentos que incumplan claramente la línea editorial.

Será el Consejo Asesor quien indique a la revista la originalidad, relevancia, estructura, redacción, aparato bibliográfico, etc. del trabajo enviado y, para ello, se designará a dos revisores expertos externos que evaluarán cada uno de los trabajos, que pueden formar parte (o no) de este Consejo Asesor. La selección de los revisores se ajustará a la temática y características metodológicas del trabajo. El nombre y filiación de los autores serán eliminados del trabajo para su revisión, así como los revisores actuarán de manera anónima y confidencial.

Los revisores deberán rellenar un informe de evaluación que centrará su atención en aspectos tales como características formales, originalidad y novedad de los trabajos, relevancia de las propuestas y los resultados, calidad metodológica y validez científica.

Una vez terminado el proceso se decidirá la aceptación o no de los mismos y su publicación en el número que sea pertinente, así como las modificaciones susceptibles de ser realizadas para su final publicación. Dicha notificación se enviará únicamente por correo electrónico, en un plazo máximo de seis meses. 


\section{Publishing rules}

The author is committed to submit original papers not having been published in other reviews or in other languages. In this way, it is not allowed for the same paper to be presented in other reviews during the evaluation process.

\section{Submission and presentation of originals}

The editing rules and the guidelines for the submission of papers can be consulted at https://revistas.um.es/pantarei/

The seventh edition of the Manual of the American Psychological Association will be taken into account for the writing of the papers. The length of the submitted papers will not exceed the 25 pages. The journal accepts originals written in Spanish or English.

\section{Examination and assessment process}

The Journal will submit the papers to a first examination once received. If the paper follows the presentation guidelines, the subject agrees with the editorial line of this journal, and possess the scientific quality required, it will be sent to the advisory council for a first assessment. If not, the documents which clearly fail to complete the editorial line may be rejected straightaway in this first step.

The Advisory Council will indicate the originality, relevance, structure, writing, bibliography, etc. of the text to the journal; for this purpose, two outside experts will be designated to review the papers; these experts can be (or not) part of this Advisory Council. The selection of the experts will adjust to the subject and methodological characteristics of the paper. Name and affiliation of the author will be eliminated from the text for its review, in this way experts will act anonymously and confidentially.

The experts will fill out an assessment report which will focus on aspects such as formal characteristics, originality and novelty of the papers, relevance and results of the proposal, methodological quality and scientific validity.

Once the process is finished, the acceptance or not of the papers and its publication in the corresponding edition will be decided, as well as the modifications that may be done for its final publication. This notification will be sent by email within 6 months maximum. 


\section{cepoAt edit.um}

